\title{
Prognostic significance of SOCS1 and SOCS3 tumor suppressors and oncogenic signaling pathway genes in hepatocellular carcinoma
}

Md Gulam Musawwir Khan ${ }^{1}$, Amit Ghosh², Bhavesh Variya², Madanraj Appiya Santharam², Awais Ullah Ihsan², Sheela Ramanathan ${ }^{1,2,3}$ and Subburaj Ilangumaran ${ }^{1,2,3^{*}}$ (i)

\begin{abstract}
Background: SOCS1 and SOCS3 genes are considered tumor suppressors in hepatocellular carcinoma (HCC) due to frequent epigenetic repression. Consistent with this notion, mice lacking SOCS1 or SOCS3 show increased susceptibility to diethylnitrosamine (DEN)-induced HCC. As SOCS1 and SOCS3 are important regulators of cytokine and growth factor signaling, their loss could activate oncogenic signaling pathways. Therefore, we examined the correlation between SOCS1/SOCS3 and key oncogenic signaling pathway genes as well as their prognostic significance in HCC.

Methods: The Cancer Genome Atlas dataset on HCC comprising clinical and transcriptomic data was retrieved from the cBioportal platform. The correlation between the expression of SOCS1 or SOCS3 and oncogenic pathway genes was evaluated using the GraphPad PRISM software. The inversely correlated genes were assessed for their impact on patient survival using the UALCAN platform and their expression quantified in the regenerating livers and DEN-induced HCC tissues of mice lacking Socs 1 or Socs3. Finally, the Cox proportional hazards model was used to evaluate the predictive potential of SOCS1 and SOCS3 when combined with the genes of select oncogenic signaling pathways.

(Continued on next page)
\end{abstract}

\footnotetext{
* Correspondence: Subburaj.Ilangumaran@Usherbrooke.ca

1 Immunology graduate program, Department of Immunology and Cell Biology, Faculty of Medicine and Health Sciences, University of Sherbrooke, 3001 North 12th avenue, Sherbrooke, QC J1H 5N4, Canada

${ }^{2}$ Cell biology graduate program, Department of Immunology and Cell Biology, Faculty of Medicine and Health Sciences, University of Sherbrooke, 3001 North 12th avenue, Sherbrooke, QC J1H 5N4, Canada

Full list of author information is available at the end of the article
}

(C) The Author(s). 2020 Open Access This article is licensed under a Creative Commons Attribution 4.0 International License, which permits use, sharing, adaptation, distribution and reproduction in any medium or format, as long as you give appropriate credit to the original author(s) and the source, provide a link to the Creative Commons licence, and indicate if changes were made. The images or other third party material in this article are included in the article's Creative Commons licence, unless indicated otherwise in a credit line to the material. If material is not included in the article's Creative Commons licence and your intended use is not permitted by statutory regulation or exceeds the permitted use, you will need to obtain permission directly from the copyright holder. To view a copy of this licence, visit http://creativecommons.org/licenses/by/4.0/ The Creative Commons Public Domain Dedication waiver (http://creativecommons.org/publicdomain/zero/1.0/) applies to the data made available in this article, unless otherwise stated in a credit line to the data. 


\begin{abstract}
(Continued from previous page)
Results: SOCS1 expression was comparable between HCC and adjacent normal tissues, yet higher SOCS1 expression predicted favorable prognosis. In contrast, SOCS3 expression was significantly low in HCC, yet it lacked predictive potential. The correlation between SOCS1 or SOCS3 expression and key genes of the cell cycle, receptor tyrosine kinase, growth factor and MAPK signaling pathways were mostly positive than negative. Among the negatively correlated genes, only a few showed elevated expression in HCC and predicted survival. Many PI3K pathway genes showed mutual exclusivity with SOCS1 and/or SOCS3 and displayed independent predictive ability. Among genes that negatively correlated with SOCS1 and/or SOCS3, only CDK2 and AURKA showed corresponding modulations in the regenerating livers and DEN-induced tumors of hepatocyte-specific Socs 1 or Socs 3 deficient mice and predicted patient survival. The Cox proportional hazards model identified the combinations of SOCS1 or SOCS3 with CXCL8 and DAB2 as highly predictive.

Conclusions: SOCS1 expression in HCC has an independent prognostic value whereas SOCS3 expression does not. The predictive potential of SOCS1 expression is increased when combined with other oncogenic signaling pathway genes.
\end{abstract}

Keywords: Hepatocellular carcinoma, SOCS1, SOCS3, TCGA, Tumor suppressor, Oncogenic signalling, Prognosis

\section{Background}

Hepatocellular carcinoma $(\mathrm{HCC})$ remains the fifth most prevalent and the third most lethal cancer worldwide despite significant advances in understanding the molecular pathogenic mechanisms $[1,2]$. New therapies targeting various oncogenic signaling pathways are in various phases of development and clinical testing [3]. The availability of mouse genetic models and transcriptomic data from The Cancer Genome Atlas (TCGA) consortium are fueling efforts to identify new therapeutic targets as well as to develop prognostic biomarkers [4-7].

Among the many genes implicated in HCC pathogenesis, the SOCS1 gene coding of suppressor of cytokine signaling 1 is repressed by epigenetic mechanisms in up to $65 \%$ of human primary HCC specimens $[8,9]$. The SOCS3 gene is also repressed in 33\% of HCC samples [10]. Cytokines and growth factors regulated by SOCS1 and SOCS3 are important players in both physiologic and neoplastic growth of hepatocytes [11-13]. We and others have studied liver regeneration in mice lacking Socs 1 or Socs 3 and their susceptibility to HCC induced by diethylnitrosamine (DEN) [14-17]. These studies reported an increased rate of liver regeneration and heightened susceptibility to DEN-induced HCC in these mice. These findings, in corroboration with clinical data on epigenetic repression of SOCS1 and SOCS3 genes in HCC specimens, clearly established non-overlapping tumor suppressor functions of SOCS1 and SOCS3 in the liver. Moreover, HCC invariably arises in cirrhotic livers, which provides not only an inflammatory environment for hepatocarcinogenesis but also increases the availability of cytokines and growth factors [12]. SOCS1 also regulates the hepatic fibrogenic response by regulating cytokine and growth factor signaling in hepatic stellate cells and in liver resident and infiltrating immune cells
$[14,18,19]$. SOCS3 also plays an anti-fibrogenic role in the liver [20]. Therefore, SOCS1 and SOCS3 may regulate hepatocyte proliferation directly as well as indirectly by modulating the liver tissue environment.

SOCS1 and SOCS3 share maximum sequence homology and structural similarity among the SOCS family members, yet significantly differ in their ability to control cytokine and growth factor signaling [21]. Whereas SOCS1 controls hepatocyte growth factor (HGF) signaling via the receptor tyrosine kinase MET [22], SOCS3 is essential to control IL-6 and epidermal growth factor receptor (EGFR) signaling [17]. SOCS1 also regulates the paradoxical oncogenic functions of the cell cycle inhibitor CDKN1A [15]. These findings imply diverse roles for SOCS1 and SOCS3 in regulating hepatocyte proliferation and neoplastic growth. Whether all these functions are compromised in primary HCC is not yet known.

To gain a deeper understanding of the tumor suppressor functions of SOCS1 and SOCS3 in HCC, and to identify the signaling pathways that are aberrantly activated in the absence of SOCS1 or SOCS3, we carried out a systematic analysis on the TCGA dataset on liver HCC (TCGALIHC) [6]. We evaluated how the expression of SOCS1 and SOCS3 genes correlates with genes implicated in hepatocarcinogenesis, emphasizing genes that regulate hepatocyte proliferation, survival and neoplastic growth. Our findings show that the expression of SOCS1 and SOCS3 negatively correlates with several genes in a similar fashion, but also show distinct regulation of some genes in several oncogenic signaling pathways. The latter could explain, at least partly, the inability of SOCS3 to compensate for the loss of SOCS1 and vice versa in animal models of HCC. We identify SOCS1 but not SOCS3 as an independent prognostic factor, whereas both display improved predictive potential when combined with certain genes of key oncogenic signaling pathways. 


\section{Methods}

\section{TCGA-LIHC dataset}

The gene expression analysis was performed on the RNAseq data from the TCGA provisional dataset on LIHC generated by the TCGA Research Network (https://www.cancer.gov/tcga) [6]. The provisional TCGA-LIHC cohort contains 442 specimens, of which RNAseq V2 data are available for 373 samples. Within this dataset, fifty samples contained paired tumor and adjacent normal tissues. The gene expression dataset was downloaded from the cBioportal suite for cancer genomics research (https://www.cbioportal.org) and analyzed using various publicly available tools as illustrated in the workflow in Supplementary Figure S1.

\section{Correlation between SOCS1/SOCS3 and oncogenic signaling pathway genes}

The various oncogenic signaling pathway genes found to be commonly affected in diverse cancers have been identified and categorized by the TCGA working groups [23]. Among these pathways, those related to cell survival and proliferation were chosen for comparative analysis with SOCS1 and SOCS3 genes. These pathways include cell cycle control (34 genes), RTK signaling and angiogenesis (19 genes), other growth/proliferation signaling and telomerase (13 genes), RAS-RAF-MEKMAPK signaling (26 genes) and PI3K-AKT-MTOR signaling (17 genes). The genes within each pathway are listed in the respective figures. Correlation between the expression of SOCS1/SOCS3 and those of the query genes in the aforementioned oncogenic signaling pathways was evaluated by Pearson's nonparametric correlation analysis (one-tailed) using the GraphPad Prism (version 8) software. The correlation coefficient ( $\rho$-value) was represented in a heatmap to reveal the relationship between SOCS1/SOCS3 and genes within the selected pathways. Statistical significance of the correlation is indicated by asterisks within the heatmap.

\section{Impact of gene expression on patient survival}

Correlation between gene expression and patient survival was analyzed using TCGA Clinical Data Resource (TCGA-CDR) available through the UALCAN platform (http://ualcan.path.uab.edu/index.html) [24, 25]. UALCAN was used to determine the expression of the query genes in tumor vs non-tumor tissues and across the tumor grades, and its relationship to patient survival. The Kaplan-Meier survival plots were generated by comparing the high expression cases (top 25\%) with moderate/ low expression (the remaining 75\%). Significance of the survival impact in these two groups was measured by log-rank (Mantel-Cox) $p$-values, or by GehanBreslow-Wilcox test as indicated.

\section{Cox proportional hazard model}

The expression levels of all genes in the selected oncogenic signaling pathways were dichotomized according to the pre-determined cut-off values of low or high expression ( $\leq 25$ th percentile and $\geq 25$ th percentile) and the remaining ( $>75$ th percentile and $<75$ th percentile). Each list was combined with the dichotomized lists for SOCS1 and SOCS3, resulting in four different dichotomous combinations (low SOCS1 + low gene-X versus rest, low SOCS1 + high gene-X vs rest, high $S O C S 1+$ low gene-X vs rest, high $S O C S 1$ + high gene-X vs rest). All possible combinations of SOCS1 or SOCS3 with all query genes were entered into a Cox proportional hazards model using the SAS software v9.4 (SAS Institute Inc., Cary, NC). A stepwise selection was used to determine the most predictive combination for patient survival (better or poor survival). The significant effects of the selected combination of variables were then validated with a univariate log-rank test for the query gene. The same procedure was applied to SOCS3.

\section{Mice, partial hepatectomy and DEN-induced HCC}

Hepatocyte-specific SOCS1-deficient mice, generated by crossing Socs $1^{f l / f l}$ mice with albumin-Cre $\left(A l b^{C r e}\right)$ mice, have been already described [15]. Socs $3^{f l f l}$ mice were purchased from the Jackson laboratories (B6;129S4Socs $3^{\text {tm1Ayos/J }}$ ) and hepatocyte-specific SOCS3-deficient mice were generated by crossing them with $A l b^{C r e}$ mice. All animal experiments were carried out with the approval of the Université de Sherbrooke Ethical committee on animal experimentation (protocol number 22617B) under the guidelines set by the Canadian Council on Animal care (CCAC). Partial hepatectomy was carried out on 8-10 weeks old mice under isoflurane anesthesia ( $2 \%$ isoflurane mixed with oxygen) as detailed previously [26], and remnant liver tissues were harvested after $24 \mathrm{~h}$. Experimental HCC was induced by the administration of diethyl nitrosamine (DEN) to 2-weeks old male pups as previously described [15]. The mice were euthanized after 8 months and macroscopic liver tumor nodules and adjacent normal tissues were resected. Euthanasia was carried out using CO2 at a 25\% flow rate under isoflurane anaesthesia. Small pieces of tissues were immersed in RNAlater (ThermoFisher) and stored at $-20{ }^{\circ} \mathrm{C}$ for gene expression analysis.

\section{Quantitative RT-PCR}

Total RNA was isolated from liver tissues using Ribo$\mathrm{Zol}^{\mathrm{TM}}$ (AMRESCO, Solon, OH). After verifying the RNA quality, the first complementary strand was made from $1 \mu \mathrm{g}$ total RNA using QuantiTect ${ }^{\circledR}$ reverse transcription kit (Qiagen). RT-PCR for gene expression analysis was carried out using the CFX-96 thermocycler (Bio-Rad, Mississauga, ON) using the primers listed in 
Supplementary Table S1. All primers showed more than 90\% efficiency with a single melting curve. Expression levels of the housekeeping gene were used to calculate fold induction of the specific genes modulated by the absence or presence of SOCS1 or SOCS3.

\section{Results}

Reduced expression of SOCS1 but not SOCS3 correlates with poor patient survival

SOCS1 expression was comparable between tumor tissues and adjacent normal tissues in the TCGA-LIHC dataset, whereas SOCS3 expression was significantly reduced in tumor tissues (Fig. 1a). SOCS1 expression was also not significantly affected across tumor grades, whereas SOCS3 expression was significantly reduced with increasing tumor grade (Fig. 1b). On the other hand, higher SOCS1 expression correlated positively with overall patient survival, whereas the SOCS3 expression level did not correlate with disease outcome (Fig. 1c). These data suggest that despite the lack of correlation with tumor stage, reduced SOCS1 expression in tumor tissues displayed an independent prognostic value, whereas reduced SOCS3 expression per se does not have a prognostic significance. Nonetheless, compelling evidence for the non-overlapping tumor suppressor functions of SOCS1 and SOCS3 from genetic models [14-17] prompted us to investigate the relationship between the expression levels of SOCS1 and SOCS3 and the key signaling pathway genes implicated in carcinogenesis.

\section{Correlation with cell cycle regulation genes}

Like in other cancers, the cell cycle pathway genes are frequently altered in HCC [23]. As SOCS1 and SOCS3 are implicated in the regulation of HGF, EGF and IL-6 signaling that promote hepatocyte proliferation and HCC pathogenesis [17, 22, 26, 27], we first evaluated the relationship between the expression of SOCS1 and SOCS3 with the cell cycle regulation genes. SOCS1 showed a significant negative correlation with six of the thirty-four cell cycle genes (STAT5B, CDK6, RBL2, $C D K 2, C C N D 1$ and $C D K N 1 B)$, whereas SOCS3 showed mutual exclusivity with only three namely, $S T A T 5 B$, $E 2 F 8$, and E2F1 (Fig. 2a). Most of these genes (STAT5B, $C D K 6, C D K 2, C D K N 1 B, E 2 F 8$, and E2F1) showed high mRNA expression in tumor tissues compared to adjacent non-tumor tissues (Fig. 2b). However, the elevated expression of most of these genes in $\mathrm{HCC}$ tumor tissues did not predict patient survival except $C D K 2$ and $E 2 F 8$, for which a higher expression was associated with poor

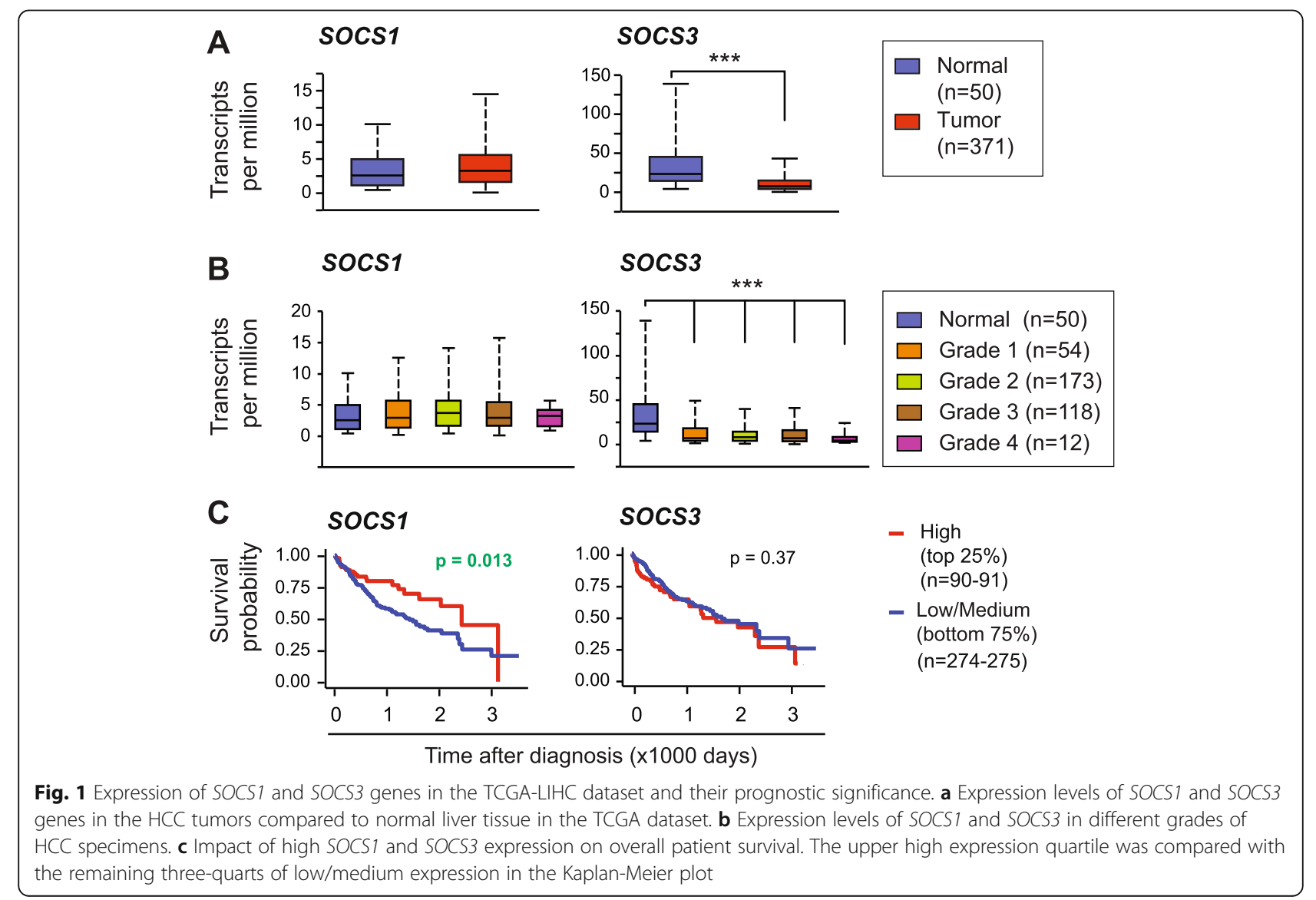




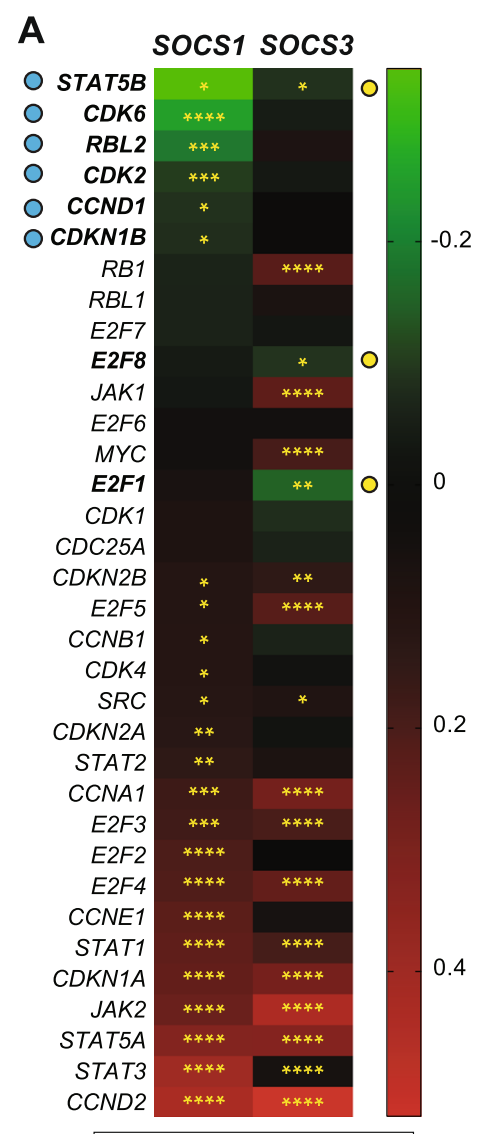

B
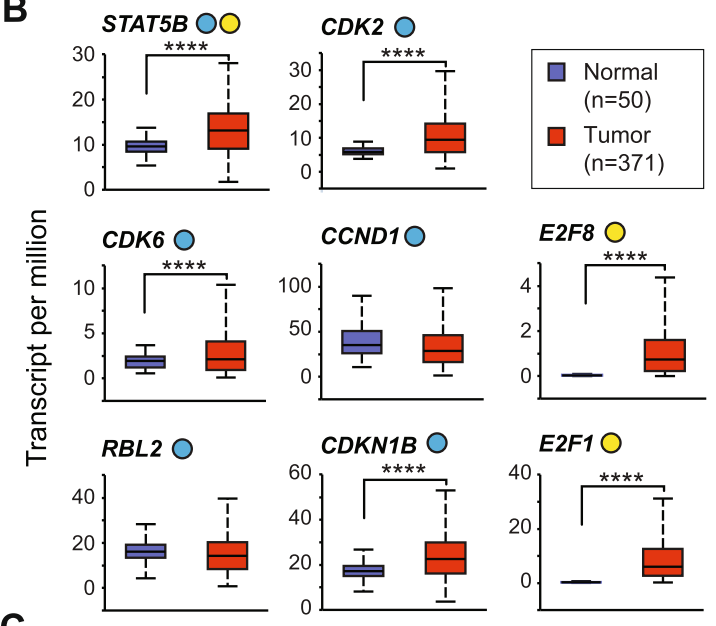

C
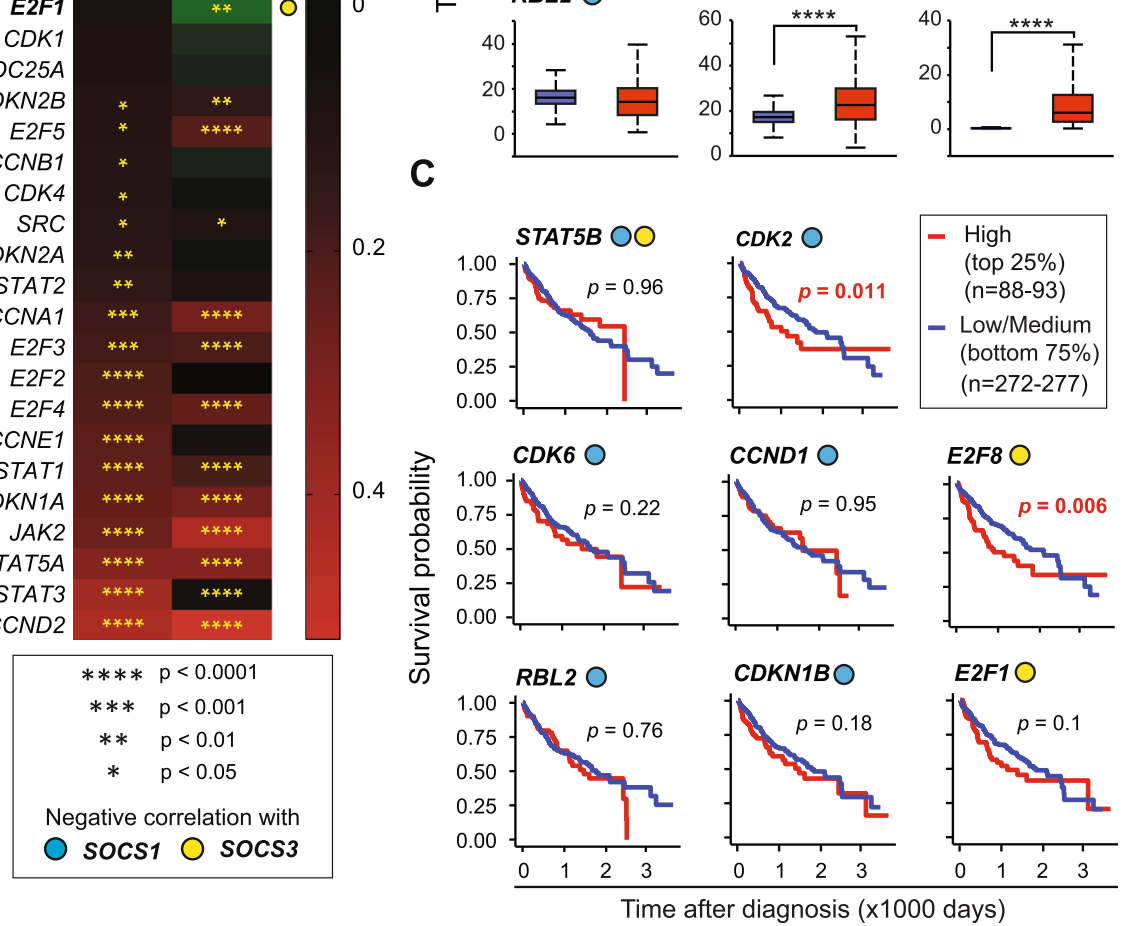

Fig. 2 Cell cycle regulation genes predominantly show a positive correlation with SOCS1 and SOCS3. a Heatmap showing negative (mutual exclusivity) or positive (co-expression) correlation between cell cycle genes and SOCS1 or SOCS3 in the TCGA-LIHC dataset. The extremities of Spearman's rank correlation coefficient ( $\rho$ ) are aligned for SOCS1, with the color scale shown at right. The $\rho$-value of -1 and 1 (green to red) implies a stronger linear relationship of mutual exclusivity and co-occurrence, respectively. Asterisks within the heatmap indicate the statistical significance of the Spearman correlation. Blue circles on the left indicate Genes showing statistically significant negative correlation with SOCS1 and yellow circles on the right mark genes showing mutual exclusivity with SOCS3. b Genes that show significant negative correlation with SOCS1 and/or SOCS3 were evaluated for their expression levels in HCC tumors compared to normal liver tissues. c Prognostic potential of the above genes was evaluated by comparing the upper quartile of high expression against the remaining three-quarts of low/medium expression by Kaplan-Meier plot. For genes showing statistically significant prognostic potential, with high gene expression correlating poor overall survival, the $p$-values are indicated in red-color font

survival (Fig. 2c). Surprisingly, many cell cycle genes showed a positive correlation with SOCS1 and SOCS3, eighteen with SOCS1 and fifteen with SOCS3 (Fig. 2a). Many of these positively correlated genes displayed the ability to independently predict poor prognosis (Supplementary Table S2). As expected, a strong positive correlation was observed for both SOCS1 and SOCS3 with STAT3 and STAT5A (Fig. 2a). In contrast, STAT5B displayed a weak mutual exclusivity with both SOCS1 and SOCS3.
RTK signaling and angiogenesis pathways

Receptor tyrosine kinase (RTK) signaling activated by growth factors HGF, EGF and IGF, which promote physiologic hepatocyte proliferation, can become oncogenic in transformed cells $[13,28]$. Some of the RTKs and certain chemokine receptors promote angiogenesis during tumor growth [29]. Out of the six genes of the angiogenesis pathway, three overlap with the sixteen driver genes of the RTK pathway. Even though the MET 
RTK is not included in the list of oncogenic RTKs pathway genes, we included MET in our study because deregulated MET signaling promotes $\mathrm{HCC}$, and SOCS1 and SOCS3 are known to regulate MET kinase activity $[23,26,27]$. Among the oncogenic RTK and angiogenesis pathway genes, a significant negative correlation was found only for ERBB2 (also known as EGFR2, HER2) and MET with both SOCS1 and SOCS3, and additionally for EGFR with SOCS1 (Fig. 3a). Among these genes, elevated expression in cancer tissues was observed for $M E T$ and ERBB2 (Fig. 3b), but neither of them predicted patient survival (Fig. 3c). Among the angiogenesis pathway genes, KDR negatively correlated with SOCS1, but SOCS3 showed a positive correlation with $K D R$ and VEGFA (Fig. 3a). Whereas VEGFA is elevated in HCC and impacts negatively on patient survival, KDR expression was not increased in HCC (Fig. 3b-c). The majority of the RTK and angiogenesis pathway genes showed a significant positive correlation with both SOCS1 and SOCS3 (Fig. 3a), and only a few of the RTK/angiogenesis pathway genes (ERBB3,VEGFA and CXCL8) displayed the ability to predict the disease outcome (Supplementary Table S2).
Other growth factors/proliferation signaling pathways and telomerase maintenance

Besides the classical growth factor signaling pathways discussed above, certain other growth factors and cell proliferation signals contribute to the pathogenesis of several cancers including HCC. This pathway includes genes coding for colony-stimulating factor-1 (CSF1) and its receptor CSF-1R, fibroblast growth factor (FGF)-FGFR and insulinlike growth factor (IGF)-IGFR systems [30-33], and a select set of less well-studied molecules implicated in carcinogenesis such as aurora kinase (AURKA) and diphthamide biosynthesis 1 (DPH1) [34, 35]. A majority of these eleven genes of this group show a positive correlation with SOCS1 and SOCS3 in the TCGA HCC dataset (Fig. 4a, Supplementary Table S2). Two key genes involved in telomerase maintenance reverse transcriptase (TERT) and the telomerase RNA component (TERC), which are critical for telomerase reactivation during HCC pathogenesis [36], are also included within this group. Notably, significant mutual exclusivity was observed for SOCS3 with TERT, TERC and AURKA, and for SOCS1 with DPH1 (Fig. 4a). All these four genes showed higher mRNA expression in HCC tumors compared to normal
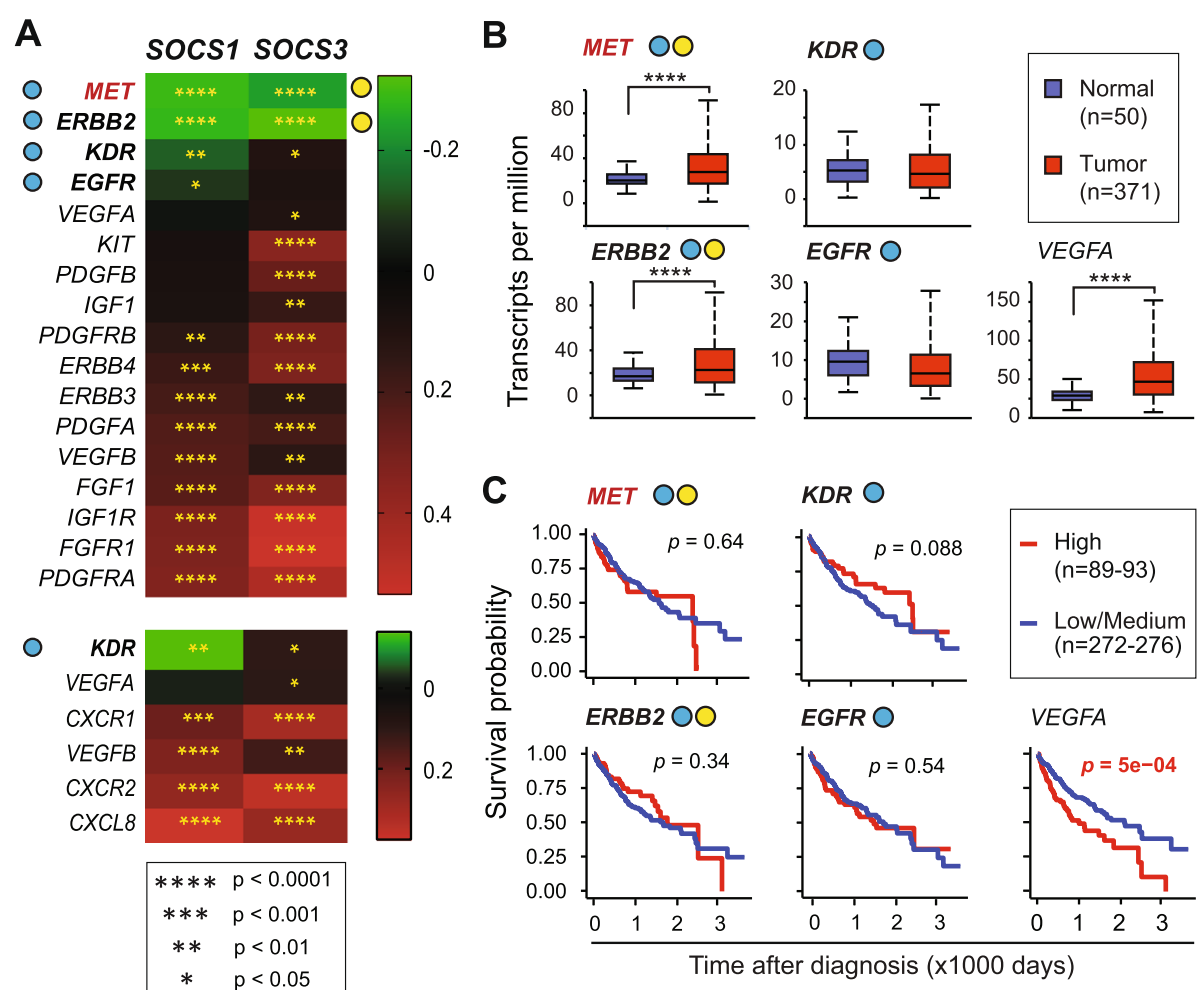

C
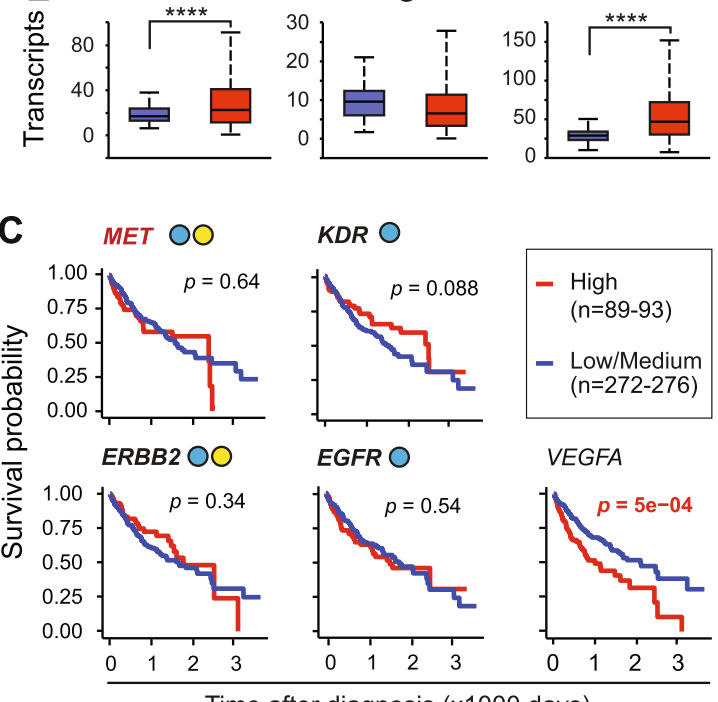

VEGFA
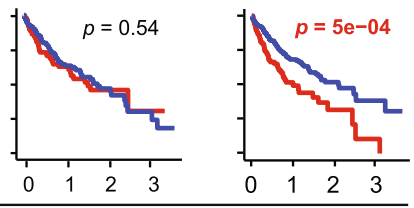

Time after diagnosis (x1000 days)

Fig. 3 Only a few RTK and angiogenesis genes show a negative correlation with SOCS1 or SOCS3. a Correlation between the expression of sixteen RTK signaling and six angiogenesis pathway (three overlapping with the RTK pathway) genes and SOCS1 or SOCS3. MET is not listed in the TCGA oncogenic signaling genes but is included for reasons detailed in the text. $\mathbf{b}$ Expression levels of genes, which show a significant negative correlation with SOCS1 and/or SOCS3, in HCC tumors and normal liver tissues. c Prognostic potential of the above genes was evaluated as described in Fig. 2c 

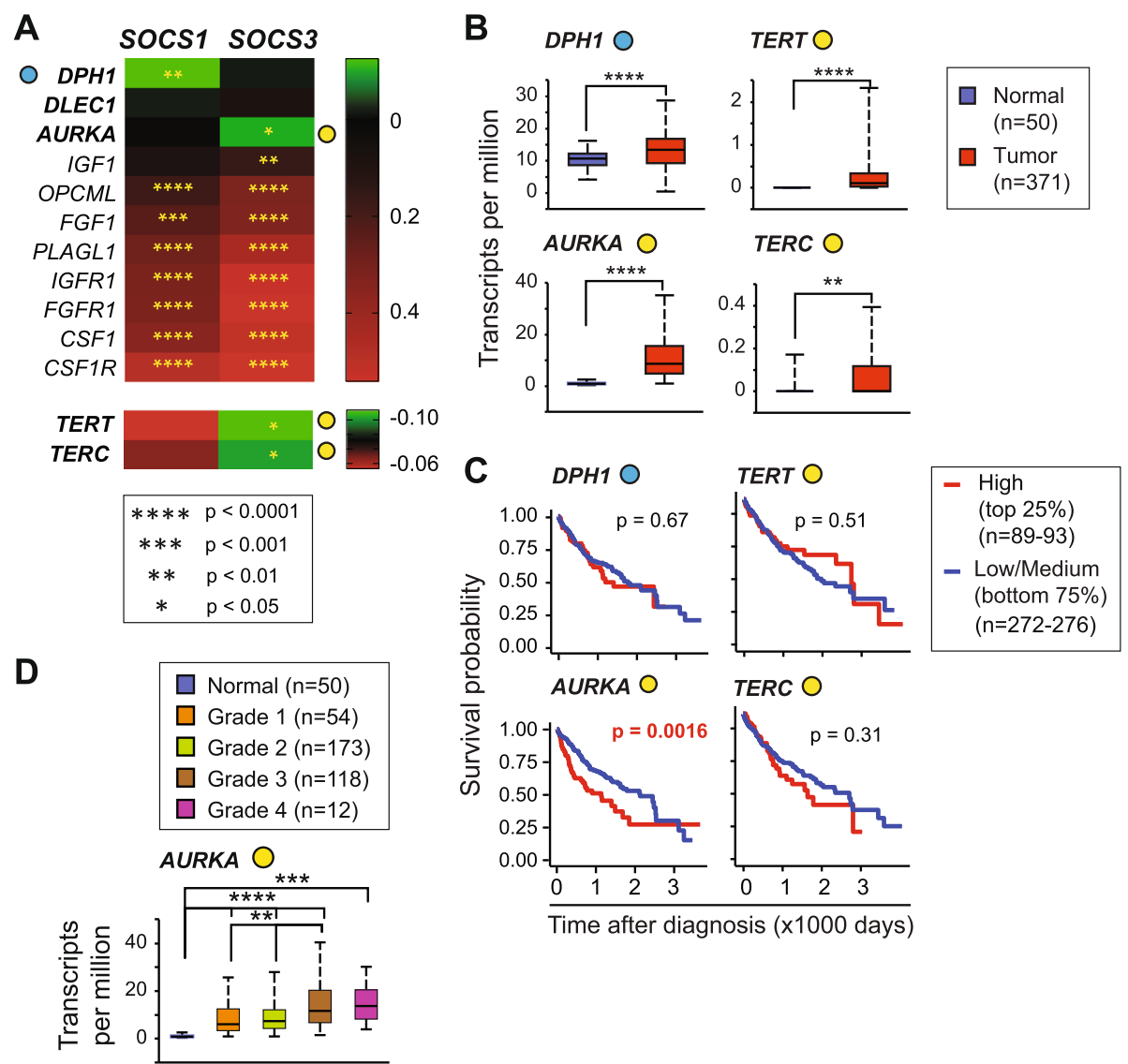

Fig. 4 AURKA expression negatively correlates with SOCS3 and predicts poor survival. a Correlation between SOCS1 and SOCS3 gene expression with other growth signaling pathway genes implicated in oncogenesis. b Expression levels of genes, which show a significant negative correlation with SOCS1 and/or SOCS3, in HCC tumors and normal liver tissues. c Predictive potential of genes that show a significant negative correlation with SOCS1 and/or SOCS3. d Expression of AURKA across the tumor grade

liver tissue (Fig. 4b). However, among them, only AURKA displayed significant predictive potential, with high expression correlating to poor survival (Fig. 4c) and its expression is significantly increased in advanced HCC (Fig. 4d). Even though long telomeres characterize HCC, TERT and $T E R C$ expression levels lacked predictive potential in the TCGA-LIHC dataset.

\section{RAS-RAF-MAPK signaling pathways}

The mitogen-activated protein kinases (MAPK) contribute to carcinogenesis via promoting many cellular functions such as cell survival, proliferation and epithelial to mesenchymal transition [37]. This pathway includes extracellular signal-regulated kinase (ERK), c-Jun Nterminal kinase (JNK) and p38 stress-activated kinase (SAPK), of which ERKs activated downstream of growth factor RTKs, and JNKs activated by inflammatory stimuli are strongly implicated in HCC pathogenesis. The canonical MAPK pathway involves activation of the RAS GTPase and RAF kinases, and then sequential activation of MAP $3 \mathrm{~K}$ and MAP $2 \mathrm{~K}$ kinases leading to MAPK activation. Activating mutations of $R A S$ and $R A F$, and inactivation/repression of endogenous regulators of RAS such as RASSF1 and DAB2 are common in many cancers including HCC [38]. Of the twenty-six oncogenic drivers of this pathway, SOCS1 showed strong mutual exclusivity with eight genes including RAF1, BRAF, MAP 2 K5, MAP 3 K2, MAPK1 (ERK2), MAPK6 (ERK3), MAPK8 (JNK1) and MAPK14 (p38 SAPK), some of which also showed a negative correlation with SOCS3 (Fig. 5a). Even though many of these negatively correlated genes are highly expressed in HCC (Fig. 5b), only MAPK1, BRAF and MAP $3 \mathrm{~K} 4$ demonstrated the ability to predict patient survival (Fig. 5c). Intriguingly, SOCS1 showed a strong positive correlation with $H R A S$ and SOCS3 with KRAS, and both with RASSF1, DAB2 and MAPK3 (ERK1) (Fig. 5a).

\section{PI3K-AKT-MTOR signaling pathway}

The PI3K-AKT-MTOR pathway, which is activated downstream of growth factor and cytokine signaling, is deregulated in multiple cancers including HCC and is 


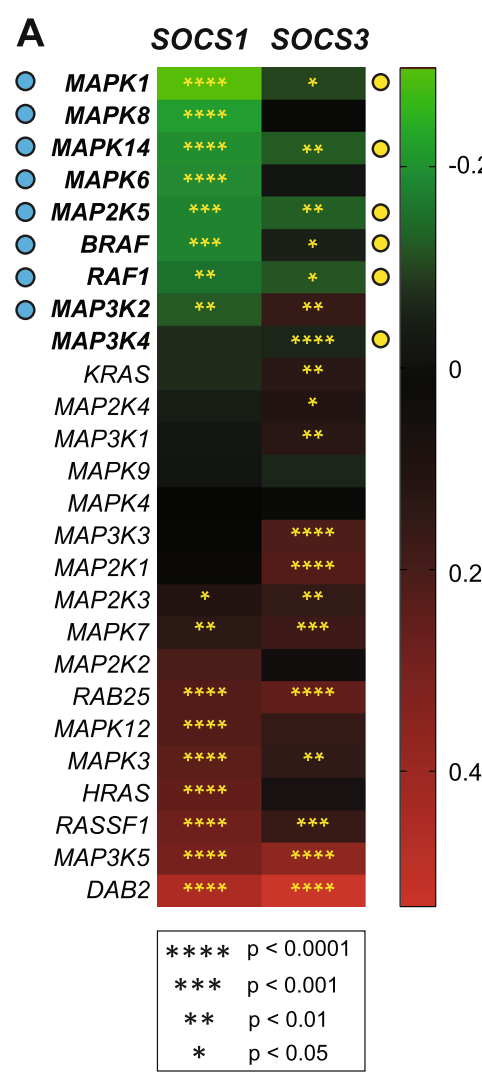

B

$\square$ Normal $(\mathrm{n}=50) \quad \square$ Tumor $(\mathrm{n}=371)$
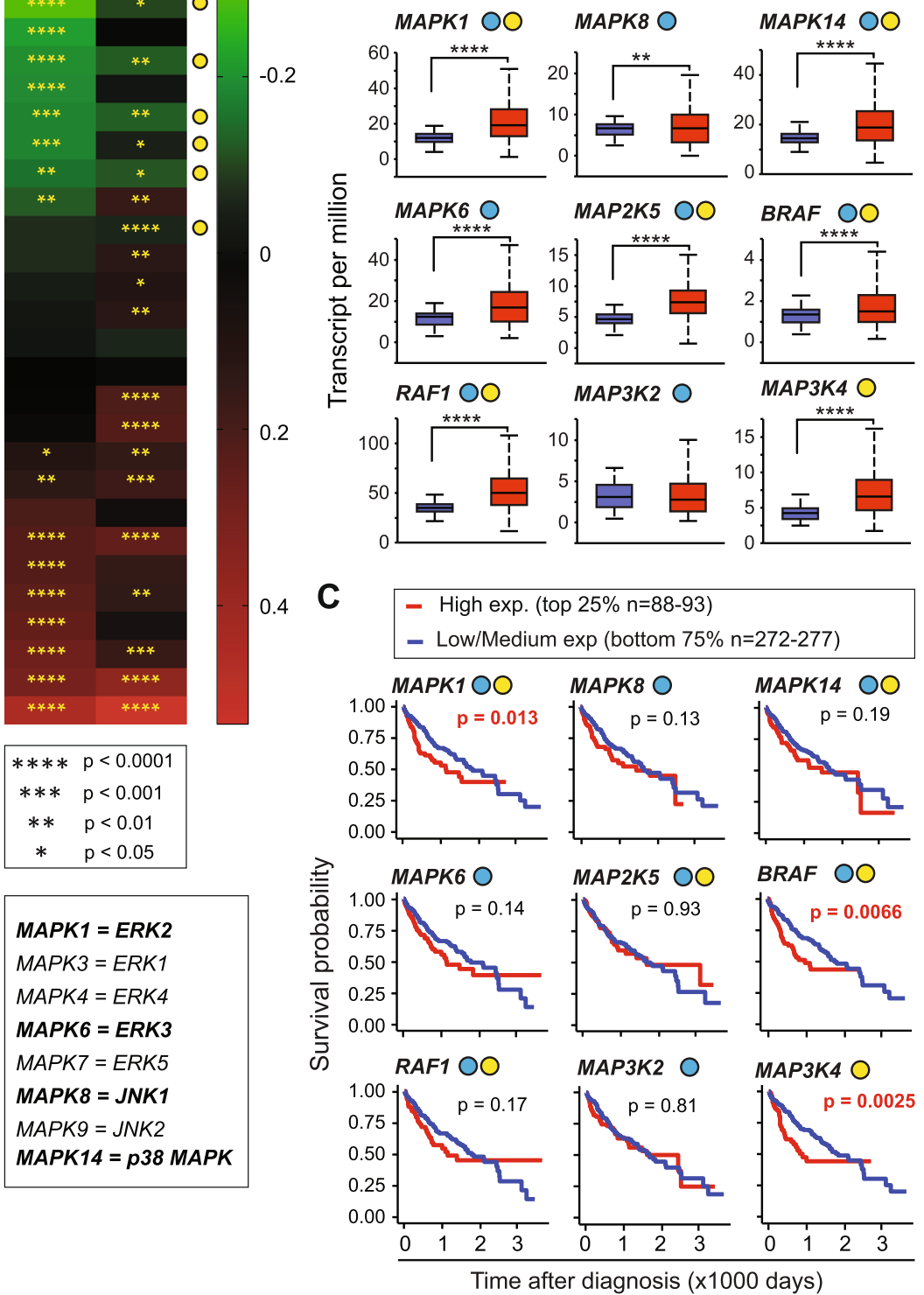

Fig. 5 Correlation between SOCS1, SOCS3 and the RAS-MAPK pathway genes and their prognostic significance. a The oncogenic RAS-RAF-MEKMAPK pathway genes were compared with SOCS1 and SOCS3 to assess mutual exclusivity and co-expression. Certain common names of genes in this pathway are indicated below. b Expression levels of genes, which show significant negative correlation with SOCS1 and/or SOCS3, in HCC tumors and normal liver tissues. c Prognostic potential of the above genes

considered an important target for therapy [39, 40]. Among the 17 genes of this pathway, five showed a negative correlation with both SOCS1 and SOCS3 (PIK3R1, PDPK1, RPTOR, PTEN, AKT2), with PIK3R1 showing the strongest mutual exclusivity (Fig. 6a). Additionally, TSC1, MTOR, and PIK3CA revealed a negative correlation only with SOCS1 whereas AKT1S1, TSC2, and MLST8 showed mutual exclusivity only with SOCS3, making PI3K-AKT-MTOR pathway the most closely related to SOCS1/SOCS3 (Fig. 7). Notably, PIK3CA (the catalytic subunit of PI3K) showed mutual exclusivity with SOCS1 but co-occurrence with SOCS3, whereas the AKT target AKT1S1 showed an inverse relationship (Fig. 6a). Among the eleven PI3K-AKT-MTOR pathway genes negatively correlated with SOCS1/SOCS3, all except PIK3CA and PIK3R1 showed significantly elevated expression in HCC tumors compared to normal liver tissue (Fig. 6b), and several of them also displayed significant independent predictive value, with high expression associated with poor survival (Fig. 6c). Intriguingly, 

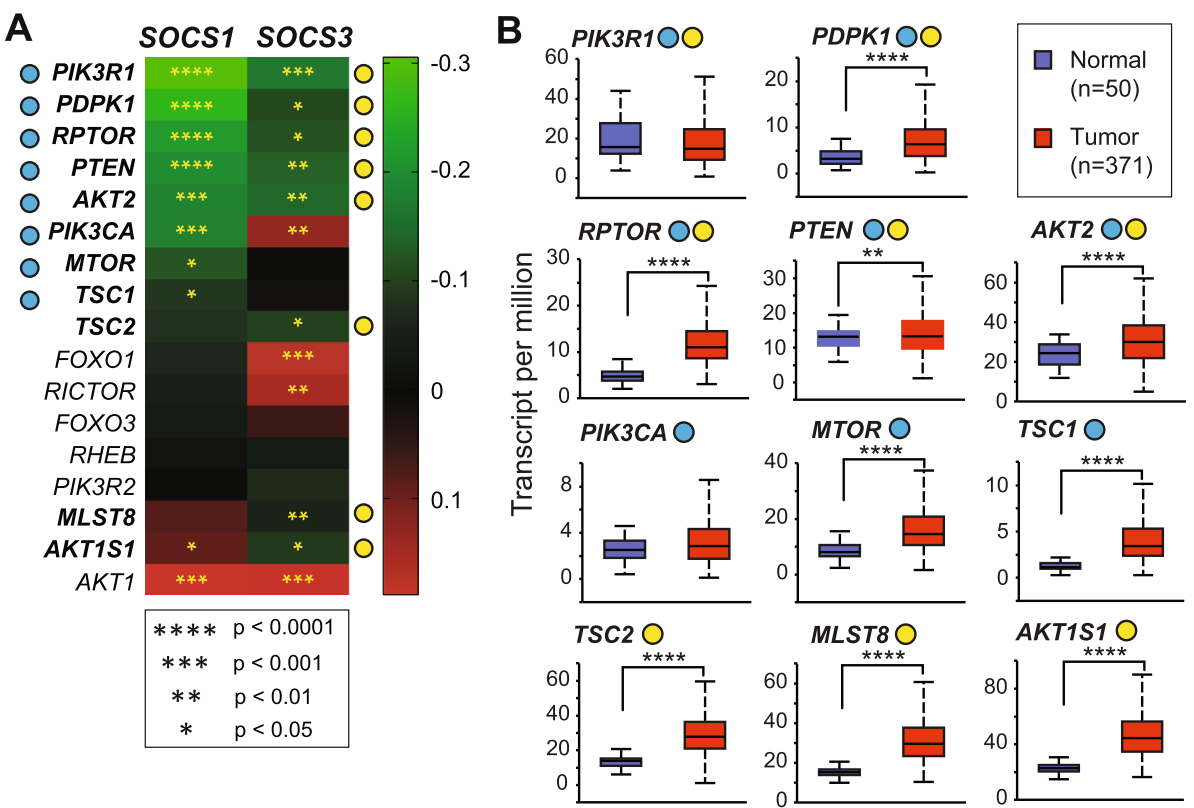

C

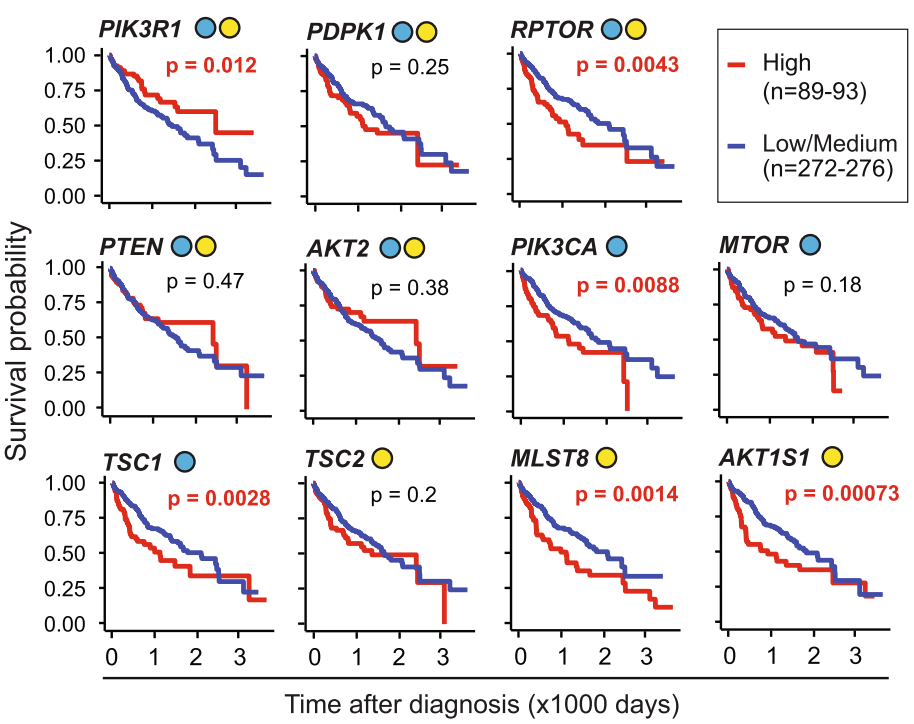

Fig. 6 PI3K-AKT pathway genes: relationship to SOCS1 and SOCS3 genes and predictive value. a Correlation between SOCS1 and SOCS3 gene expression with thePI3K-AKT-MTOR signaling pathway genes implicated in oncogenesis. b Expression levels of genes, which show a significant negative correlation with SOCS1 and/or SOCS3, in HCC tumors and normal liver tissues. c Predictive value of the above genes. Note that the high expression of PIK3R1 predicts better prognosis

elevated expression of PIK3R1, which showed a negative correlation with SOCS1 and SOCS3, was associated with a better disease outcome (Fig. 6c).

As SOCS1 and SOCS3 are tumor suppressors implicated in regulating cytokine and growth factor signaling pathways, we expected a predominantly inverse correlation between SOCS1/SOCS3 and oncogenic signaling pathway genes implicated in HCC. However, this was only observed within the PI3K-AKT-MTOR pathway (Fig. 7; Supplementary Table S2). Among the genes that showed a negative correlation with SOCS1 and/or
SOCS3, nine genes with high expression in tumor tissues predicted poor prognosis, whereas low expression of PIK3R1 was associated with bad prognosis (Table 1).

\section{Validation of genes that inversely correlated to SOCS1 or} SOCS3 expression

Next, we used mice lacking SOCS1 or SOCS3 in hepatocytes to validate key oncogenic signaling pathway genes that negatively correlated with SOCS1 or SOCS3 in the TCGA-LIHC dataset. Physiological hepatocyte proliferation was induced in $\operatorname{Socs} 1^{f l f f l} A l b^{C r e}$, Socs $3^{f l f l} A l b^{C r e}$ and 


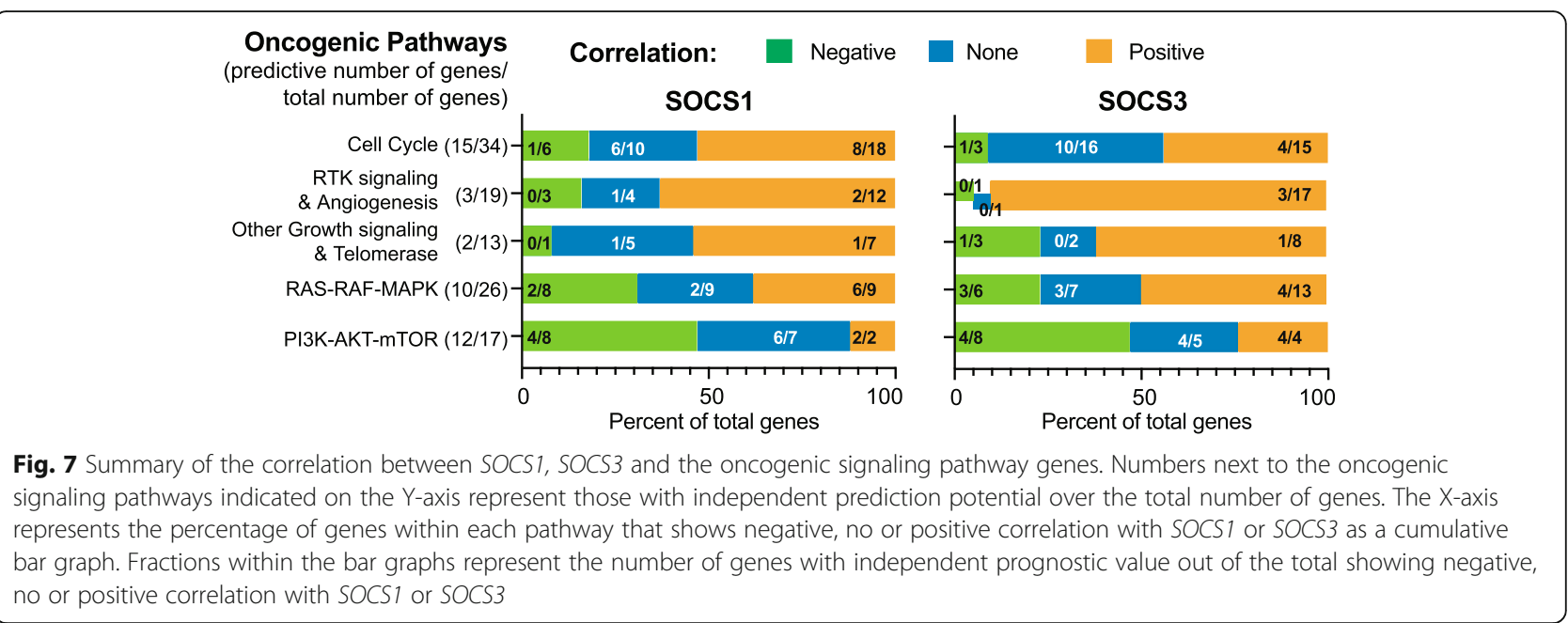

Socs $1^{f l f l}$ Socs $3^{f l f l}$ control mice by partial hepatectomy $(\mathrm{PH})$, and gene expression was evaluated in regenerating livers $24 \mathrm{~h}$ later (Fig. 8a). To study gene expression associated with pathological hepatocyte proliferation, HCC was induced in hepatocyte-specific SOCS1- or SOCS3- deficient mice using the hepatocarcinogen DEN (Fig. 8b). Liver tumor nodules and adjacent non-tumor tissues, obtained 8-10 months after DEN injection, were evaluated for gene expression.

$C d k 2$, which is negatively correlated with SOCS1 expression in the TCGA dataset, was significantly upregulated in SOCS1-deficient liver following $\mathrm{PH}$ as well as in DEN-induced HCC (Fig. 8a-b). Similarly, Aurka, which is negatively correlated with SOCS3 in the TCGA dataset, was upregulated more than 100-fold in SOCS3deficient, but not in SOCS1-deficient liver, following $\mathrm{PH}$ and in DEN-induced HCC (Fig. 8a-b). In contrast to Aurka, Mlst8 and Map 3 k4, which are negatively correlated with SOCS3 in the TCGA dataset, were not affected by SOCS3 deficiency in the regenerating livers or in $\mathrm{HCC}$ tissues, although discernible upregulation of Mlst8 was observed in the absence of SOCS1 (Fig. 8a-b). RPTOR, which is negatively correlated with both SOCS1 and SOCS3 in the TCGA dataset, was increased in the regenerating livers of mice lacking SOCS1 in hepatocytes but not in SOCS3-deficient livers. These results show that some of the negative correlations between SOCS1 or $S O C S 3$ and the oncogenic signaling pathway genes, notably CDK2 and AURKA, observed in the TCGA dataset are recapitulated in SOCS1- and SOCS3- deficient livers.

Next we evaluated the predictive potential of SOCS1 and SOCS3 when combined with the high expression of

Table 1 Genes that negatively correlate with SOCS1 and/or SOCS3 and their impact on patient survival. * High expression predicts better survival, for all others poor survival

\begin{tabular}{|c|c|c|c|c|}
\hline SOCS & Negatively correlated genes & Oncogenic signaling Pathway & $\begin{array}{l}\text { Upregulation in tumor vs normal } \\
p \text { value }\end{array}$ & $\begin{array}{l}\text { Survival } \\
\text { Probability } \\
p \text { value }\end{array}$ \\
\hline SOCS1 & - & - & No difference & 0.013 \\
\hline \multirow[t]{2}{*}{ SOCS1 } & CDK2 & Cell cycle regulation & 0.0001 & 0.011 \\
\hline & $P I K 3 R 1^{*}$ & PI3K-AKT-MTOR & No difference & $(0.012)^{*}$ \\
\hline \multirow[t]{5}{*}{ SOCS3 } & E2F8 & Cell cycle regulation & 0.0001 & 0.006 \\
\hline & AKTIS1 & PI3K-AKT-MTOR & 0.0001 & 0.00073 \\
\hline & MLST8 & PI3K-AKT-MTOR & 0.0001 & 0.0014 \\
\hline & AURKA & Other Growth signaling & 0.0001 & 0.0016 \\
\hline & MAP 3 K4 & RAS-RAF-MEK-MAPK & 0.0001 & 0.0025 \\
\hline \multirow{3}{*}{$\begin{array}{l}\text { SOCS1, } \\
\text { SOCS3 }\end{array}$} & RPTOR & PI3K-AKT-MTOR & 0.0001 & 0.0043 \\
\hline & BRAF & RAS-RAF-MEK-MAPK & 0.0001 & 0.0066 \\
\hline & MAPK1 & RAS-RAF-MEK-MAPK & 0.0001 & 0.013 \\
\hline
\end{tabular}

*High expression predicts better survival, for all others poor survival 


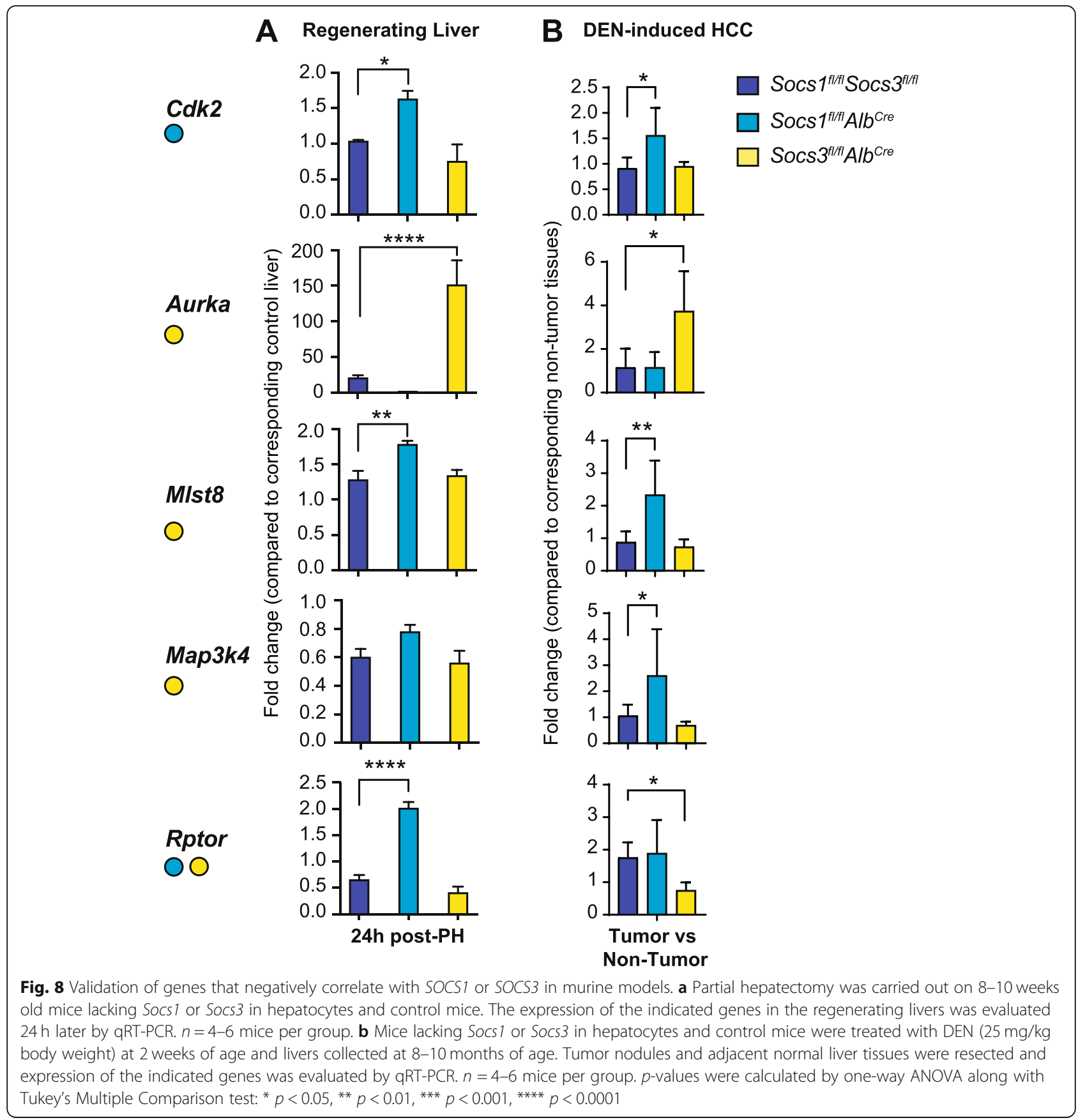

candidate genes from each oncogenic signaling pathway that showed a negative correlation. As shown in Fig. 9, TCGA-LIHC specimens displaying low SOCS1/high $C D K 2$, low SOCS3/high AURKA and low SOCS3/high $M A P 3 K 4$ expression displayed poor prognosis with a hazard ration of more than 2.5 compared to low SOCS1/ low CDK2, low SOCS3/low AURKA and low SOCS3/low $M A P 3 K 4$ groups, respectively. On the other hand, the predictive potential of high MLST8 and RPTOR expression was not observed within low SOCS1 or low SOCS3 groups.
Impact of oncogenic signaling genes on the predictive potential of SOCS1 and SOCS3

Next, we used the Cox proportional hazards model to evaluate the predictive potential of SOCS1 and SOCS3 when combined with oncogenic signaling pathway genes. Even though a high expression of many oncogenic signaling pathway genes independently predicted poor survival (Supplementary Table S2) and some of them showed a better prognostic potential when combined with SOCS1/ SOCS3 (CDK2, AURKA and MAP 3 K4; Fig. 9), the Cox model revealed a different set of genes with prognostic 
A
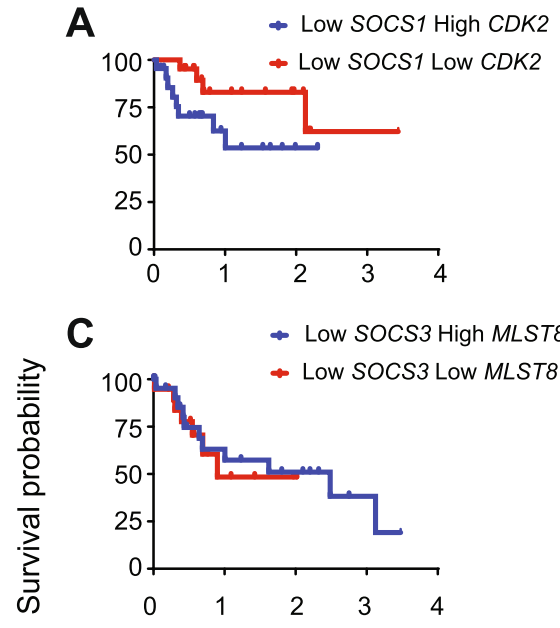

E

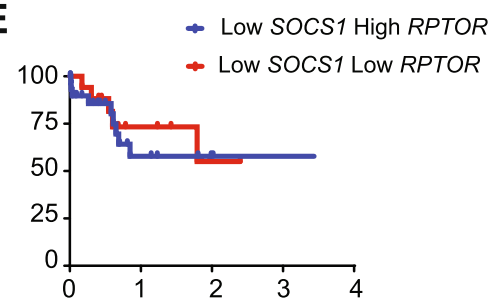

B

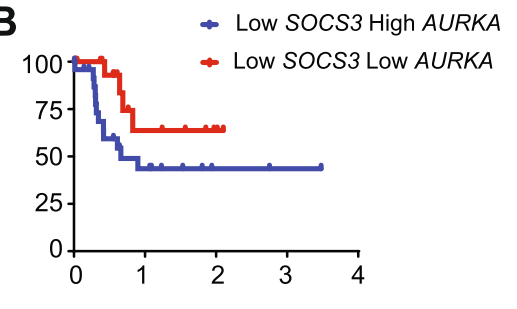

D

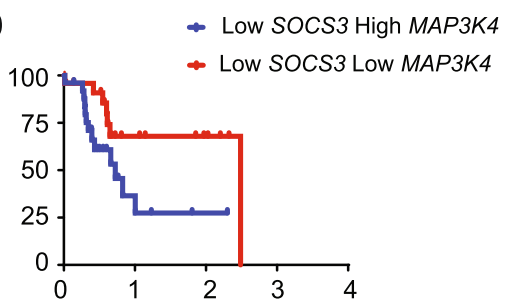

$\mathbf{F}$

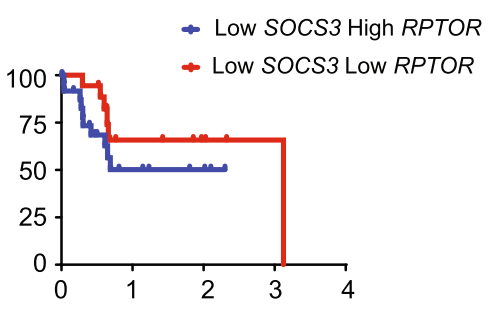

G

Time after diagnosis (x1000 days)

\begin{tabular}{lclllllll}
\hline Group 1 & $\mathbf{n 1}$ & Group 2 & $\mathbf{n 2}$ & $\begin{array}{l}\text { p:Log-rank } \\
\text { (Mantel-Cox) } \\
\text { test }\end{array}$ & $\begin{array}{l}\text { p: Gehan- } \\
\text { Breslo- } \\
\text { Wilcoxon } \\
\text { test }\end{array}$ & $\begin{array}{l}\text { Hazard } \\
\text { Ratio } \\
\text { (Mantel- } \\
\text { Haenszel) }\end{array}$ & $\begin{array}{l}\text { Hazard } \\
\text { Ratio } \\
\text { (log-rank) }\end{array}$ & Prognosis \\
\hline $\begin{array}{l}\text { Lo SOCS1 } \\
\text { Hi CDK2 }\end{array}$ & 22 & $\begin{array}{l}\text { Lo SOCS1 } \\
\text { Lo CDK2 }\end{array}$ & 21 & $\underline{0.081}$ & $\mathbf{0 . 0 4 5 4}$ & $\mathbf{2 . 8 0 7}$ & $\mathbf{2 . 7 5 3}$ & poor \\
$\begin{array}{l}\text { Lo SOCS3 } \\
\text { Hi AURKA }\end{array}$ & 25 & $\begin{array}{l}\text { Lo SOCS3 } \\
\text { Lo AURKA }\end{array}$ & 20 & $\underline{0.0791}$ & $\mathbf{0 . 0 2 7 7}$ & $\mathbf{2 . 4 1 4}$ & $\mathbf{2 . 6 4 6}$ & poor \\
$\begin{array}{l}\text { Lo SOCS3 } \\
\text { Hi MLST8 }\end{array}$ & 24 & $\begin{array}{l}\text { Lo SOCS3 } \\
\text { Lo MLST8 }\end{array}$ & 21 & 0.7627 & 0.7323 & 0.8553 & 0.8704 & \\
$\begin{array}{l}\text { Lo SOCS3 } \\
\text { Hi MAP3K4 }\end{array}$ & 25 & $\begin{array}{l}\text { Lo SOCS3 } \\
\text { Lo MAP3K4 }\end{array}$ & 25 & $\mathbf{0 . 0 3 5 1}$ & $\underline{0.0526}$ & $\mathbf{2 . 6 6 8}$ & $\mathbf{2 . 5 2 6}$ & poor \\
$\begin{array}{l}\text { Lo SOCS1 } \\
\text { Hi RPTOR }\end{array}$ & 31 & $\begin{array}{l}\text { Lo SOCS1 } \\
\text { Lo RPTOR }\end{array}$ & 17 & 0.7909 & 0.6573 & 1.157 & 1.159 & \\
$\begin{array}{l}\text { Lo SOCS3 } \\
\text { Hi RPTOR }\end{array}$ & 26 & $\begin{array}{l}\text { Lo SOCS3 } \\
\text { Lo RPTOR }\end{array}$ & 18 & 0.2205 & 0.1315 & 1.886 & 1.826 & \\
\hline
\end{tabular}

Fig. 9 Predictive potential of combining low SOCS1 or SOCS3 expression along with high expression of oncogenic pathway genes in the TCGA dataset. a-f Specimens in the TCGA-LIHC dataset with low SOCS1 or SOCS3 expression were segregated into those displaying high or low expression of CDK2, AURKA, MLST8, MAP 3 K4 or RPTOR and compared for patient survival by Kaplan-Meier plot. $\mathbf{g}$ The number of specimens within each group, the $p$-values calculated by the log-rank and Gehan-Breslow-Wilcoxon tests, the hazard ratios and prognostic potential are shown

potential (Table 2, Supplementary Table S3). Notably, low SOCS1 displayed a significant predictive potential in combination with CDK1, CXCL8, CSF1, DAB2 and TSC1, with $C X C L 8$ and $D A B 2$ showing the highest hazards ratio. $C X C L 8$ and $D A B 2$ also predicted poor survival in combination with low SOCS3, even though the latter did not display independent predictive ability. A limitation of this analysis is that some combination groups, especially low SOCS1 or SOCS3 and high CXCL8, had only a very few cases out of a total of 362 cases. In contrast to low expression, high SOCS1 levels showed limited synergy with most other genes in predicting better survival (Supplementary 
Table 2 Predictive potential of SOCS1/SOCS3 and oncogenic signalling pathway in the Cox proportional hazard model

\begin{tabular}{|c|c|c|c|c|c|c|}
\hline $\begin{array}{l}\text { Selected gene } \\
\text { Combinations }\end{array}$ & $\begin{array}{l}\text { Oncogenic signaling } \\
\text { Pathway }\end{array}$ & $\begin{array}{l}\text { Multivariate } \\
\text { Cox model } \\
p \text {-value }\end{array}$ & $\begin{array}{l}\text { Univariate log-rank } \\
p \text {-value }\end{array}$ & $\begin{array}{l}\text { Survival } \\
\text { probability }\end{array}$ & $\begin{array}{l}\text { Number of } \\
\text { subjects }\end{array}$ & $\begin{array}{l}\text { HR }[95 \% \text { confidence } \\
\text { intervals] }\end{array}$ \\
\hline $\begin{array}{l}\text { Low SOCS1 } \\
+ \text { High CDK1 }\end{array}$ & Cell cycle & 0.0152 & 0.0153 & Poor & 17 & $2.56[1.28-5.11]$ \\
\hline $\begin{array}{l}\text { Low SOCS1 } \\
+ \text { High CXCL8 }\end{array}$ & $\begin{array}{l}\text { RTK signalling, } \\
\text { angiogenesis }\end{array}$ & $<0.0001$ & $<0.0001$ & Poor & 4 & $7.97[2.85-22.25]$ \\
\hline $\begin{array}{l}\text { Low SOCS1 } \\
+ \text { High IGFIR }\end{array}$ & $\begin{array}{l}\text { RTK signalling, } \\
\text { angiogenesis }\end{array}$ & 0.0051 & 0.007 & Poor & 6 & $5.98[2.09-17.13]$ \\
\hline $\begin{array}{l}\text { Low SOCS1 } \\
+ \text { High CSF1 }\end{array}$ & Proliferation & 0.0042 & 0.0042 & Poor & 11 & $2.62[1.19-5.78]$ \\
\hline $\begin{array}{l}\text { Low SOCS1 } \\
+ \text { High DAB2 }\end{array}$ & MAPK pathway & $<0.0001$ & $<0.0001$ & Poor & 8 & $7.73[3.45-17.35]$ \\
\hline $\begin{array}{l}\text { Low SOCS1 } \\
+ \text { LOW PIK3R1 }\end{array}$ & PI3K-AKT pathway & 0.0102 & 0.0102 & Poor & 9 & $3.52[1.55-8.01]$ \\
\hline $\begin{array}{l}\text { Low SOCS1 } \\
+ \text { High TSC1 }\end{array}$ & PI3K-AKT pathway & 0.0248 & 0.0274 & Poor & 24 & $2.84[1.50-5.38]$ \\
\hline $\begin{array}{l}\text { Low SOCS1 } \\
+ \text { High RAF1 }\end{array}$ & MAPK pathway & 0.0046 & 0.0291 & Better & 28 & $0.281[0.11-0.71]$ \\
\hline $\begin{array}{l}\text { Low SOCS1 } \\
+ \text { High AKT1S1 }\end{array}$ & PI3K-AKT pathway & 0.0034 & 0.0187 & Better & 15 & $0.08[0.02-0.36]$ \\
\hline $\begin{array}{l}\text { Low SOCS1 } \\
+ \text { Low PIK3R2 }\end{array}$ & PI3K-AKT pathway & 0.0192 & 0.0344 & Better & 28 & $0.224[.08-0.65]$ \\
\hline $\begin{array}{l}\text { Low SOCS3 } \\
+ \text { High RBL1 }\end{array}$ & Cell cycle & 0.0053 & 0.0123 & Poor & 23 & 2.20 [1.20-4.03] \\
\hline $\begin{array}{l}\text { Low SOCS3 } 3^{\mathrm{a}} \\
+ \text { High CXCL8 }\end{array}$ & $\begin{array}{l}\text { RTK signalling, } \\
\text { angiogenesis }\end{array}$ & 0.0017 & 0.0017 & Poor & 3 & $7.03[1.70-28.99]$ \\
\hline $\begin{array}{l}\text { Low SOCS3 } \\
+ \text { High FGFR1 }\end{array}$ & Proliferation & 0.0125 & 0.0173 & Poor & 4 & $4.15[1.31-13.17]$ \\
\hline $\begin{array}{l}\text { Low SOCS3 } 3^{\mathrm{a}} \\
+ \text { Low DLEC1 }\end{array}$ & Proliferation & 0.0163 & 0.0324 & Poor & 22 & $2.01[1.12-3.58]$ \\
\hline $\begin{array}{l}\text { Low SOCS3 } \\
+ \text { High } D A B 2\end{array}$ & MAPK pathway & 0.0023 & 0.0023 & Poor & 10 & $3.42[1.49-7.84]$ \\
\hline $\begin{array}{l}\text { Low SOCS } 3^{\mathrm{a}} \\
+ \text { High PIK } 3 R 1^{\mathrm{b}}\end{array}$ & PI3K-AKT pathway & 0.0232 & 0.0232 & Better & 27 & $0.21[0.07-0.6]$ \\
\hline
\end{tabular}

All possible combinations of SOCS1 or SOCS3 with all query genes were analysed in the Cox proportional hazards model as described in materials and methods. High or low expression of individual genes have poor prognosis in univariate analysis unless indicated otherwise: ${ }^{\mathrm{a}}$ No prognostic value; ${ }^{\mathrm{b}} \mathrm{Good}$ prognosis. Genes in bold face show synergy with both low SOCS1 and low SOCS3

Table S3). Notably, high SOCS1 even lost its favorable prognostic value in tumors with high E2F7, which independently predicts poor survival.

Even though high $C X C L 8$ and $D A B 2$ transcript levels synergized with low SOCS1 or SOCS3 expression to predict high hazards ratio in the Cox model (Table 2), CXCL8 and DAB2 showed positive correlation with SOCS1 and SOCS3 in the TCGA-LIHC dataset (Figs. 3 and 5) and their high expression independently predicted poor prognosis (Supplementary Table S2) whereas high SOCS1 expression predicted favorable outcome (Fig. 1). Therefore, we examined whether SOCS1 and SOCS3 influenced the expression of CXCL8 and $D A B 2$ genes in the mouse models of liver regeneration and DEN-induced HCC. As the CXCL8 (IL-8) gene is absent in rodents, we examined the genes coding for mouse chemokines KC (Cxcl1), MIP-2 (Cxcl2) and LIX $(\mathrm{Cxcl} 2)$, which are considered the functional equivalents of human CXCL8 in promoting neutrophil migration [41]. As shown in Supplementary Figure S2, Cxcl1, Cxcl2 and $\mathrm{Cxcl5}$ genes showed significantly elevated expression in the regenerating livers of mice lacking SOCS3 or SOCS1, whereas Cxcl1 was upregulated and Cxcl2 and Cxcl5 were downregulated in DEN-induced HCC tissues of both mice compared to control mice. The expression of Dab2 was not affected by the loss of either SOCS1 or SOCS3 in the mouse liver undergoing physiological or pathological hepatocyte proliferation. These findings suggest (i) the positive correlations between CXCL8 or $D A B 2$ and SOCS1 or SOCS3 observed in the TCGALIHC dataset likely results from deregulated signaling pathways in the tumor tissues and (ii) the elevated 
CXCL8 expression worsens the prognosis of cases with low SOCS1 or SOCS3 expression as CXCL8 is implicated in promoting tumor angiogenesis [42].

\section{Discussion}

Our study has revealed notable differences in the prognostic utility of SOCS gene expression compared to epigenetic repression. Specifically, methylation of the SOCS1 gene, which occurs in up to $65 \%$ of HCC specimens $[8,9]$, is not reflected in SOCS1 mRNA expression within the TCGA dataset. On the other hand, the SOCS3 gene, reported to be repressed only in 33\% of HCC cases [10], showed reduced expression in the TCGA dataset. Whereas methylation data based on a positive PCR product reflects the repressed status of the gene in hepatocytes, it is possible that induction of the SOCS gene expression in liver-resident and infiltrating immune cells and hepatic stromal cells by a myriad of cytokines and growth factors might contribute to the overall SOCS1 transcript levels in the TCGA dataset. In support of this possibility, SOCS1 mRNA expression positively correlated with CD247 (CD3 zeta chain, all T cells), CD8A (CD8 ${ }^{+} \mathrm{T}$ cells), NCAM1 (CD56, NK cells) and IFNG (activated $\mathrm{T}$ and NK cells) (data not shown). Nonetheless, even though SOCS1 mRNA expression was not significantly different between tumor and normal tissues, higher transcript levels strongly correlated with patient survival (Fig. 1c), highlighting the potential prognostic utility of SOCS1 expression in HCC.

The positive correlations in the expression of SOCS1/ SOCS3 and the oncogenic signaling pathway genes may result from the induction of intact SOCS1 and SOCS3 genes as part of the negative feedback regulatory mechanisms to control oncogenic signaling. On the other hand, the negative correlations could arise either from increased oncogenic signaling due to reduced SOCS1/ SOCS3 expression, as well as from reduced oncogenic signaling due to increased SOCS1/SOCS3 expression. Moreover, SOCS1 and SOCS3 might target certain transcriptional activators or repressors as substrate specific adaptors in ubiquitin-mediated proteasomal degradation [43]. Thus, the loss of SOCS1 or SOCS3 may also affect the oncogenic pathway gene expression indirectly.

As in other cancers, uncontrolled cell cycle progression is a key feature of HCC that results from aberrant expression of cell cycle proteins and/or their regulators [44]. Under conditions of increased cyclin D1 availability, for example from increased growth factor signaling, CDK2 promotes hepatocyte proliferation [45]. CDK2 is a potential therapeutic target in many cancers including HCC [46]. While high CDK2 expression, either alone or along with low SOCS1 expression, correlated with poor survival in our study (Fig. 2c, Fig. 8c), Sonntag et al., [47] did not find significant prognostic value for $C D K 2$, possibly because the latter used the median value to separate the low and high expression groups, whereas in our study we compared the high one-quartile group and the remaining with low/medium expression.

RTK signaling in hepatocytes and endothelial cells is a key promoter of HCC pathogenesis [28, 48]. Indeed, deregulation of this pathway by genomic alterations is over-represented in the TCGA-LIHC dataset, and drugs targeting this pathway such as Sorafenib and Regorafenib are already being used or in advanced clinical trials $[2,6,48]$. However, it is widely perceived that a drug choice based on biomarker analysis could improve the treatment outcome. Key RTK signaling/angiogenesis genes $M E T, E R B B 2, K D R$ and EGFR, all implicated in HCC [49-52], negatively correlate with SOCS1, and the first two with SOCS3 as well. Deregulated EGFR and KDR signaling can contribute to Sorafenib resistance in advanced HCC $[51,53]$. However, none of these four genes were able to independently predict patient survival within the TCGA-LIHC dataset (Fig. 3c). This notion is supported by the failure of MET-targeting therapeutics to improve survival outcome that has been recently attributed, at least partly, to the ability of kinase-inhibited MET to promote cell survival [54]. Even though MET expression alone was not predictive, ERBB3, which contributes to the resistance to MET inhibition [55] displayed a high predictive potential (Supplementary Table S2). Similarly, even though KDR was not predictive, its ligand VEGFA showed a very strong predictive potential (Fig. 3c). These findings identify ERBB3 and VEGFA as potential biomarkers for targeted therapies. CXCL8 (IL-8), a chemokine secreted by inflammatory cells including activated HSCs, induces angiogenic growth factors such as VEGFA in HCC cells and promotes angiogenesis [56]. Strikingly, $C X C L 8$, which shows a strong negative prognosis in HCC, displayed marked synergy with low SOCS1 or SOCS3 in multivariate analysis (Table 2), suggesting the potential use of these markers together. Indeed, CXCL8 receptor (CXCR1, CXCR2) antagonists [57] could be an important addition to targeted therapeutics in HCC.

The only gene within the other proliferation signaling pathway that showed prognostic potential was AURKA, which is a biomarker for cancer development and progression, and a potential target for therapy in $\operatorname{HCC}[58,59]$. AURKA expression is dramatically high in TCGA-LIHC dataset, with a significantly increased expression as the disease progresses, and displays a strong predictive ability for disease outcome either alone or along with SOCS3 (Fig. 4b-d, Fig. 8c; Table 1). The negative correlation between AURKA and SOCS3 is also highlighted by a more than 100-fold increase in Aurka expression in the regenerating livers of hepatocyte-specific SOCS3-deficient mice, and significant upregulation of this gene in DEN-induced HCC in these mice (Fig. 8a-b). One possible mechanism 
by which SOCS3 could modulate AURKA expression could be via p53, which represses AURKA [60]. SOCS3 can promote transcriptional activation of p53 [20]. Whether SOCS3 can also modulate the repressive function of p53 is not known. It is noteworthy that SOCS1, which was shown to activate p53 earlier [61], did not correlate with AURKA expression in the TCGA dataset. Clearly, further studies are needed to elucidate the mutual exclusivity of SOCS3 and AURKA expression in HCC.

The RAS-RAF-MAPK pathway is frequently perturbed in HCC and thus is an important therapeutic target [62]. Indeed, the RAF kinase is a key target of Sorafenib that is already used in HCC therapy. Immunohistochemical analysis of HCC specimens in a Chinese cohort revealed a prognostic value for RAF1 [63]. Even though RAF1 expression is elevated in the TCGA-LIHC dataset, it did not have prognostic potential. On the other hand, BRAF1 and MAP 3 K4 (MEKK4), which are inversely correlated to SOCS3 expression, was found to be upregulated in TCGA-LIHC and displayed a high predictive potential. It is noteworthy that $B R A F$, which also negatively correlates with $S O C S 1$, has been previously reported to be commonly found in cholangiocarcinoma but not in HCC [64]. The negative regulators of the RAS-RAF-MAPK pathway, which inhibit RAS activity (RASSF1A, RASSF2A, RASSF5, RASAL1) or inhibit the RAF kinase (SPRED1, SPRED2) are frequently repressed by promoter methylation in HCC $[38,65]$. DAB2, which attenuates the RAS activation downstream of RTK signaling, is also repressed by promoter methylation [66]. RASSF1A and DAB2 showed coordinate regulation with SOCS1 and SOCS3. As promoter hypermethylation also represses SOCS1 and SOCS3, it is possible that epigenetic repression of both SOCS genes as well as the endogenous negative regulators the RAS-RAF-MAPK pathway likely contributes to their coordinate regulation that amplifies the proliferation and anti-apoptotic functions of this pathway, contributing to HCC pathogenesis.

Surprisingly, high expression of RASSF1 and DAB2 predicted poor survival in the TCGA-HCC dataset (Supplementary Table S2), instead of a better prognosis expected of their function as negative regulators of the RAS-MAPK pathway. High DAB2 expression within low SOCS1 or SOCS3 expressing subgroups also predicted poor overall survival in the multivariate analysis (Table 2). The reason for this apparent discrepancy is unclear. It is possible that the upregulation of RASSF1 and DAB2 may result from mutations that disrupt the normal functions of these tumor suppressors, as in the case of mutant p53, which is highly expressed in many cancers [67]. However, only a negligible proportion of cases in the TCGA dataset revealed mutations for RASSF1 or DAB2 (data not shown). It is equally possible that their increased expression could result from a compensatory increase in response to the increased activity of this pathway or mutations in their target proteins. Clearly further studies are needed to resolve this conundrum.

The MTOR pathway is frequently activated in HCC and is associated with poor prognosis [40]. Our findings reveal that out of eleven driver genes of the PI3K-AKTMTOR pathway analyzed, RPTOR, PIK3CA, TSC1, MLST8 and AKT1S1 showed a pronounced negative impact on patient survival whereas PIK3R1 showed favorable impact (Fig. 6c), raising the possibility of using these genes as prognostic markers. Both SOCS1 and SOCS3 have been implicated in regulating the PI3KAKT pathway upstream of MTOR. By their ability to promote ubiquitination and proteasomal degradation of insulin receptor substrates 1 and 2 (IRS1, IRS2), which link RTK signaling to PI3K, SOCS1 and SOCS3 can regulate AKT activation in the context of insulin resistance in the liver and other organs [68, 69]. We have shown that SOCS1-deficient primary hepatocytes show increased AKT activation in response to HGF [26]. Our findings show that the expression of both SOCS1 and SOCS3 shows a high degree of mutual exclusivity with PIK3R1 (Fig. 6a). Even though this gene codes for the p85 regulatory subunit of PI3K, there is strong evidence indicating that PIK3R1 also functions as a tumor suppressor by modulating PTEN, AKT and STAT3 [70-72]. Consistent with this role, high PIK3R1 predicts favorable survival in our analysis (Table 1). Given the tumor suppressor functions and overlapping mechanisms of action of SOCS1, SOCS3 and PIK3R1, further work is needed to disentangle the highly significant negative correlation between SOCS1/SOCS3 and PIK3R1.

\section{Conclusions}

Our findings show that SOCS1 gene expression in HCC has a significant prognostic value that is further improved when combined with other markers, although studies in other cohorts are needed to confirm these findings. We observed coordinated expression of several oncogenic signaling pathway genes and SOCS1/SOCS3, presumably reflecting activation of negative feedback loops. However, nearly half of the PI3K-AKT-MTOR pathway genes showed mutual exclusivity with SOCS1/SOCS3, suggesting the loss of SOCS-dependent regulation of RTKs contributing to the increased activity of this signaling pathway. Finally, our study identified at least three genes, RASSF 1 and DAB2 in the RAS- MAPK pathway and PIK3R1 in the PI3K-AKT pathway that showed a predictive value opposite of their expected functions, which warrant further investigations. Collectively, SOCS1 and certain key genes of the oncogenic signaling pathways that show high predictive value in this study could be developed further as combination biomarkers for patient-oriented precision therapeutics in HCC. 


\section{Supplementary information}

Supplementary information accompanies this paper at https://doi.org/10. 1186/s12885-020-07285-3.

\section{Additional file 1: Figure S1. Workflow of this study. Figure S2.}

Expression of oncogenic signaling pathway genes that synergize with SOCS1 or SOCS3 in predicting prognosis by the Cox proportional harzards model in the murine models. DAB2 and CXCL8 synergize with SOCS1 or SOCS3 in predicting prognosis by the Cox proportional harzards model (shown in Table 2). As the CXCL8 (IL-8) gene is not present in the mouse, we examined the genes coding for mouse chemokines KC ( $\mathrm{C} x \mathrm{C} / 1)$, MIP-2 $(\mathrm{C} x \mathrm{C} / 2)$ and LIX (CxCl2), which are considered the functional equivalent of human CXCL8 in promoting neutrophil migration.(A) Partial hepatectomy was carried out on 8-10 weeks old mice lacking Socs 1 or Socs3 in hepatocytes and control mice. The expression of the indicated genes in the regenerating livers was evaluated $24 \mathrm{~h}$ later by qRT-PCR. $n=4-6$ mice per group. (B) Mice lacking Socs 1 or Socs 3 in hepatocytes and control mice were treated with DEN (25 mg/kg body weight) at 2 weeks of age and livers collected at $8-10$ months of age. Tumor nodules and adjacent normal liver tissues were resected and expression of the indicated genes was evaluated by qRT-PCR. $n=4-6$ mice per group. $p$-values were calculated by one-way ANOVA along with Tukey's Multiple Comparison test: * $p<0.0001$. Table S1. List of qRT-PCR primers used in this study. Table S2. Impact of the expression of oncogenic pathway genes on survival probability in the TCGA-LIHC dataset. Table S3. Combinations of high SOCS1 or high SOCS3 and oncogenic signalling pathway genes that show significant prognosis in the Cox proportional hazard model.

\section{Abbreviations}

DEN: Diethyl nitrosamine; HCC: Hepatocellular carcinoma; TCGA-LIHC: The Cancer Genome Atlas - Liver HCC; SOCS: Suppressor of cytokine signaling

\section{Acknowledgments}

We thank Ms. Marie-Pierre Garant of the CRCHUS for the Cox proportional hazard analysis.

\section{Authors' contributions}

Conceptualization, M.K., S.R., and S.I.; Data Analysis and interpretation, M.K., M. S, B.V., A.I., and A.G.; Experiments, M.K., S.R., and A.G.; Manuscript drafting and editing, M.K., M. S., S.R., and S.I. All authors have read the manuscript and approved the final version.

\section{Funding}

The Canadian Institutes of Health Research (Project grant \#PJT-153174 to SI) provided funding support to the design, analysis and data interpretation of this study and its publication. MK received a doctoral scholarship from FRQN T. MR was supported by the 'Abdenour-Nabid MD' graduate fellowship of the Faculty of Medicine and Health Sciences, Université de Sherbrooke. Al is a recipient of the 'VoiceAge' graduate fellowship from the Université de Sherbrooke. AG is a recipient of a postdoctoral fellowship from the Fonds de la recherche en santé du Québec (FRQS).

\section{Availability of data and materials}

The TCGA-LIHC datasets analysed in the current study are available through the cBioportal suite for cancer genomics research (https://www.cbioportal.org).

\section{Ethics approval and consent to participate}

As this work analyses the TCGA data on human HCC available through public databases, ethical approval is not required. However, as suggested by the TCGA consortium, the original publication of the LIHC data is quoted in the bibliography. All animal experiments were carried out with the approval of the Université de Sherbrooke Ethical committee on animal experimentation (protocol number 226-17B) in accordance with the guidelines set by the Canadian Council on Animal care (CCAC).

\section{Consent for publication}

Not applicable.

\section{Competing interests}

The authors declare that they have no competing interests.

\section{Author details}

Immunology graduate program, Department of Immunology and Cell Biology, Faculty of Medicine and Health Sciences, University of Sherbrooke, 3001 North 12th avenue, Sherbrooke, QC J1H 5N4, Canada. ${ }^{2}$ Cell biology graduate program, Department of Immunology and Cell Biology, Faculty of Medicine and Health Sciences, University of Sherbrooke, 3001 North 12th avenue, Sherbrooke, QC J1H 5N4, Canada. ${ }^{3} \mathrm{CRCHUS}$, Sherbrooke, Québec J1H 5N4, Canada.

Received: 13 April 2020 Accepted: 10 August 2020

Published online: 17 August 2020

\section{References}

1. Torre LA, Bray F, Siegel RL, Ferlay J, Lortet-Tieulent J, Jemal A. Global cancer statistics, 2012. CA Cancer J Clin. 2015;65(2):87-108.

2. Llovet JM, Villanueva A, Lachenmayer A, Finn RS. Advances in targeted therapies for hepatocellular carcinoma in the genomic era. Nat Rev Clin Oncol. 2015:12(7):408-24.

3. Kudo M. Targeted and immune therapies for hepatocellular carcinoma: predictions for 2019 and beyond. World J Gastroenterol. 2019;25(7):789-807.

4. Fausto N, Campbell JS. Mouse models of hepatocellular carcinoma. Semin Liver Dis. 2010;30(1):87-98.

5. Liu YF, Zha BS, Zhang HL, Zhu XJ, Li YH, Zhu J, Guan XH, Feng ZQ, Zhang $J P$. Characteristic gene expression profiles in the progression from liver cirrhosis to carcinoma induced by diethylnitrosamine in a rat model. J Exp Clin Cancer Res. 2009:28:107.

6. Cancer Genome Atlas Research Network. Electronic address wbe, Cancer genome atlas research $\mathrm{N}$ : comprehensive and integrative genomic characterization of hepatocellular carcinoma. Cell. 2017;169(7):1327-41 e1323.

7. Xue R, Chen L, Zhang C, Fujita M, Li R, Yan SM, Ong CK, Liao X, Gao Q, Sasagawa $S$, et al. Genomic and transcriptomic profiling of combined hepatocellular and intrahepatic cholangiocarcinoma reveals distinct molecular subtypes. Cancer Cell. 2019;35(6):932-47 e938.

8. Yoshikawa H, Matsubara K, Qian GS, Jackson P, Groopman JD, Manning JE, Harris CC, Herman JG. SOCS-1, a negative regulator of the JAK/STAT pathway, is silenced by methylation in human hepatocellular carcinoma and shows growth- suppression activity. Nat Genet. 2001;28(1):29-35.

9. Yang B, Guo M, Herman JG, Clark DP. Aberrant promoter methylation profiles of tumor suppressor genes in hepatocellular carcinoma. Am J Pathol. 2003;163(3):1101-7.

10. Niwa $Y$, Kanda H, Shikauchi $Y$, Saiura A, Matsubara K, Kitagawa T, Yamamoto J, Kubo T, Yoshikawa H. Methylation silencing of SOCS-3 promotes cell growth and migration by enhancing JAK/STAT and FAK signalings in human hepatocellular carcinoma. Oncogene. 2005;24(42):6406-17.

11. Taub R. Liver regeneration: from myth to mechanism. Nat Rev Mol Cell Biol. 2004:5(10):836-47.

12. Farazi PA, DePinho RA. Hepatocellular carcinoma pathogenesis: from genes to environment. Nat Rev Cancer. 2006:6(9):674-87.

13. Whittaker S, Marais R, Zhu AX. The role of signaling pathways in the development and treatment of hepatocellular carcinoma. Oncogene. 2010; 29(36):4989-5005

14. Yoshida T, Ogata H, Kamio M, Joo A, Shiraishi H, Tokunaga Y, Sata M, Nagai $\mathrm{H}$, Yoshimura A. SOCS1 is a suppressor of liver fibrosis and hepatitis-induced carcinogenesis. J Exp Med. 2004;199(12):1701-7.

15. Yeganeh M, Gui Y, Kandhi R, Bobbala D, Tobelaim WS, Saucier C, Yoshimura A, Ferbeyre G, Ramanathan S, llangumaran S. Suppressor of cytokine signaling 1-dependent regulation of the expression and oncogenic functions of p21(CIP1/WAF1) in the liver. Oncogene. 2016:35(32):4200-11.

16. Ogata H, Kobayashi T, Chinen T, Takaki H, Sanada T, Minoda Y, Koga K, Takaesu G, Maehara Y, lida M, et al. Deletion of the SOCS3 gene in liver parenchymal cells promotes hepatitis-induced hepatocarcinogenesis. Gastroenterology. 2006;131(1):179-93.

17. Riehle KJ, Campbell JS, McMahan RS, Johnson MM, Beyer RP, Bammler TK, Fausto N. Regulation of liver regeneration and hepatocarcinogenesis by suppressor of cytokine signaling 3. J Exp Med. 2008;205(1):91-103.

18. Kandhi R, Bobbala D, Yeganeh M, Mayhue M, Menendez A, llangumaran S. Negative regulation of the hepatic fibrogenic response by suppressor of cytokine signaling 1. Cytokine. 2016;82:58-69.

19. Mafanda EK, Kandhi R, Bobbala D, Khan MGM, Nandi M, Menendez A Ramanathan S, llangumaran S. Essential role of suppressor of cytokine 
signaling 1 (SOCS1) in hepatocytes and macrophages in the regulation of liver fibrosis. Cytokine. 2018;124:154501.

20. Kong $X$, Feng D, Wang H, Hong F, Bertola A, Wang FS, Gao B. Interleukin-22 induces hepatic stellate cell senescence and restricts liver fibrosis in mice. Hepatology. 2012;56(3):1150-9.

21. Khan MGM, Ghosh A, Variya B, Santharam MA, Kandhi R, Ramanathan S, Ilangumaran S. Hepatocyte growth control by SOCS1 and SOCS3. Cytokine. 2019;121:154733.

22. Gui Y, Yeganeh M, Donates YC, Tobelaim WS, Chababi W, Mayhue M, Yoshimura A, Ramanathan S, Saucier C, Ilangumaran S. Regulation of MET receptor tyrosine kinase signaling by suppressor of cytokine signaling 1 in hepatocellular carcinoma. Oncogene. 2015;34:5718-28.

23. Sanchez-Vega F, Mina M, Armenia J, Chatila WK, Luna A, La KC, Dimitriadoy S, Liu DL, Kantheti HS, Saghafinia S, et al. Oncogenic signaling pathways in the Cancer genome atlas. Cell. 2018;173(2):321-37 e310.

24. Liu J, Lichtenberg T, Hoadley KA, Poisson LM, Lazar AJ, Cherniack AD, Kovatich AJ, Benz CC, Levine DA, Lee AV, et al. An integrated TCGA PanCancer clinical data resource to drive high-quality survival outcome analytics. Cell. 2018;173(2):400-16 e411.

25. Chandrashekar DS, Bashel B, Balasubramanya SAH, Creighton CJ, PonceRodriguez I, Chakravarthi B, Varambally S. UALCAN: a portal for facilitating tumor subgroup gene expression and survival analyses. Neoplasia. 2017; 19(8):649-58.

26. Gui Y, Yeganeh M, Ramanathan S, Leblanc C, Pomerleau V, Ferbeyre G, Saucier C, llangumaran S. SOCS1 controls liver regeneration by regulating HGF signaling in hepatocytes. J Hepatol. 2011;55(6):1300-8.

27. Seki $E$, Kondo $Y$, limuro $Y$, Naka T, Son G, Kishimoto T, Fujimoto J, Tsutsui $H$, Nakanishi K. Demonstration of cooperative contribution of MET- and EGFRmediated STAT3 phosphorylation to liver regeneration by exogenous suppressor of cytokine signalings. J Hepatol. 2008;48(2):237-45.

28. Huynh H, Ong RW, Li PY, Lee SS, Yang S, Chong LW, Luu DA, Jong CT, Lam IW. Targeting receptor tyrosine kinase pathways in hepatocellular carcinoma. Anti Cancer Agents Med Chem. 2011;11(6):560-75.

29. Zhu AX, Duda DG, Sahani DV, Jain RK. HCC and angiogenesis: possible targets and future directions. Nat Rev Clin Oncol. 2011;8(5):292-301.

30. Ao JY, Zhu XD, Chai ZT, Cai H, Zhang YY, Zhang KZ, Kong LQ, Zhang N, Ye BG, $\mathrm{Ma} \mathrm{DN}$, et al. Colony-stimulating Factor 1 receptor blockade inhibits tumor growth by altering the polarization of tumor-associated macrophages in hepatocellular carcinoma. Mol Cancer Ther. 2017;16(8):1544-54.

31. Sandhu DS, Baichoo $E$, Roberts $L R$. Fibroblast growth factor signaling in liver carcinogenesis. Hepatology. 2014;59(3):1166-73.

32. Jo JC, Choi EK, Shin JS, Moon JH, Hong SW, Lee HR, Kim SM, Jung SA, Lee $\mathrm{DH}$, Jung SH, et al. Targeting FGFR pathway in human hepatocellular carcinoma: expressing PFGFR and pMET for antitumor activity. Mol Cancer Ther. 2015;14(11):2613-22.

33. Enguita-German $M$, Fortes $P$. Targeting the insulin-like growth factor pathway in hepatocellular carcinoma. World J Hepatol. 2014;6(10):716-37.

34. Su ZL, Su CW, Huang YL, Yang WY, Sampurna BP, Ouchi T, Lee KL, Wu CS, Wang HD, Yuh CH. A novel AURKA mutant-induced early-onset severe Hepatocarcinogenesis greater than wild-type via activating different pathways in zebrafish. Cancers (Basel). 2019;11(7):1

35. Liu M, Yin K, Guo X, Feng H, Yuan M, Liu Y, Zhang J, Guo B, Wang C, Zhou G, et al. Diphthamide biosynthesis 1 is a novel oncogene in colorectal Cancer cells and is regulated by MiR-218-5p. Cell Physiol Biochem. 2017;44(2):505-14.

36. Nault JC, Ningarhari M, Rebouissou S, Zucman-Rossi J. The role of telomeres and telomerase in cirrhosis and liver cancer. Nat Rev Gastroenterol Hepatol. 2019;16(9):544

37. Min L, He B, Hui L. Mitogen-activated protein kinases in hepatocellular carcinoma development. Semin Cancer Biol. 2011;21(1):10-20.

38. Delire B, Starkel P. The Ras/MAPK pathway and hepatocarcinoma: pathogenesis and therapeutic implications. Eur J Clin Investig. 2015;45(6):609-23.

39. Zhang Y, Kwok-Shing Ng P, Kucherlapati M, Chen F, Liu Y, Tsang YH, de Velasco G, Jeong KJ, Akbani R, Hadjipanayis A, et al. A Pan-Cancer Proteogenomic atlas of PI3K/AKT/mTOR pathway alterations. Cancer Cell. 2017;31(6):820-32 e823.

40. Matter MS, Decaens T, Andersen JB, Thorgeirsson SS. Targeting the mTOR pathway in hepatocellular carcinoma: current state and future trends. J Hepatol. 2014;60(4):855-65.

41. Hol J, Wilhelmsen L, Haraldsen G. The murine IL-8 homologues KC, MIP-2, and LIX are found in endothelial cytoplasmic granules but not in WeibelPalade bodies. J Leukoc Biol. 2010;87(3):501-8.
42. Waugh DJ, Wilson C. The interleukin-8 pathway in cancer. Clin Cancer Res. 2008;14(21):6735-41.

43. Ilangumaran S, Ramanathan S, Rottapel R. Regulation of the immune system by SOCS family adaptor proteins. Semin Immunol. 2004;16(6): $351-65$.

44. Bisteau X, Caldez MJ, Kaldis P. The complex relationship between liver Cancer and the cell cycle: a story of multiple regulations. Cancers (Basel). 2014;6(1):79-111.

45. Hanse EA, Nelsen CJ, Goggin MM, Anttila CK, Mullany LK, Berthet C, Kaldis P, Crary GS, Kuriyama R, Albrecht JH. Cdk2 plays a critical role in hepatocyte cell cycle progression and survival in the setting of cyclin D1 expression in vivo. Cell Cycle. 2009:8(17):2802-9.

46. Tadesse S, Caldon EC, Tilley W, Wang S. Cyclin-dependent kinase 2 inhibitors in Cancer therapy: an update. J Med Chem. 2019;62(9):4233-51.

47. Sonntag R, Giebeler N, Nevzorova YA, Bangen JM, Fahrenkamp D, Lambertz D, Haas U, Hu W, Gassler N, Cubero FJ, et al. Cyclin E1 and cyclin-dependent kinase 2 are critical for initiation, but not for progression of hepatocellular carcinoma. Proc Natl Acad Sci U S A. 2018;115(37):9282-7.

48. Morse MA, Sun W, Kim R, He AR, Abada PB, Mynderse M, Finn RS. The role of angiogenesis in hepatocellular carcinoma. Clin Cancer Res. 2019;25(3):912-20.

49. Giordano S, Columbano A. Met as a therapeutic target in HCC: facts and hopes. J Hepatol. 2014;60(2):442-52.

50. Shi JH, Guo WZ, Jin Y, Zhang HP, Pang C, Li J, Line PD, Zhang SJ. Recognition of HER2 expression in hepatocellular carcinoma and its significance in postoperative tumor recurrence. Cancer Med. 2019;8(3):1269-78.

51. Negri FV, Dal Bello B, Porta C, Campanini N, Rossi S, Tinelli C, Poggi G, Missale G, Fanello S, Salvagni S, et al. Expression of pERK and VEGFR-2 in advanced hepatocellular carcinoma and resistance to sorafenib treatment. Liver Int. 2015;35(8):2001-8.

52. Berasain C, Avila MA. The EGFR signalling system in the liver: from hepatoprotection to hepatocarcinogenesis. J Gastroenterol. 2014;49(1):9-23.

53. Blivet-Van Eggelpoel MJ, Chettouh H, Fartoux L, Aoudjehane L, Barbu V, Rey C, Priam S, Housset C, Rosmorduc O, Desbois-Mouthon C. Epidermal growth factor receptor and HER-3 restrict cell response to sorafenib in hepatocellular carcinoma cells. J Hepatol. 2012;57(1):108-15.

54. Huang X, Gan G, Wang X, Xu T, Xie W. The HGF-MET axis coordinates liver cancer metabolism and autophagy for chemotherapeutic resistance. Autophagy. 2019;15(7):1258-79.

55. Steinway SN, Dang H, You H, Rountree CB, Ding W. The EGFR/ErbB3 pathway acts as a compensatory survival mechanism upon c-met inhibition in human c-met+ hepatocellular carcinoma. PLoS One. 2015; 10(5):e0128159.

56. Zhu B, Lin N, Zhang M, Zhu Y, Cheng H, Chen S, Ling Y, Pan W, Xu R. Activated hepatic stellate cells promote angiogenesis via interleukin-8 in hepatocellular carcinoma. J Transl Med. 2015;13:365.

57. Li L, Khan MN, Li Q, Chen X, Wei J, Wang B, Cheng JW, Gordon JR, Li F. G31P, CXCR1/2 inhibitor, with cisplatin inhibits the growth of mice hepatocellular carcinoma and mitigates highdose cisplatin-induced nephrotoxicity. Oncol Rep. 2015;33(2):751-7.

58. Dauch D, Rudalska R, Cossa G, Nault JC, Kang TW, Wuestefeld T, Hohmeyer A, Imbeaud S, Yevsa T, Hoenicke L, et al. A MYC-aurora kinase a protein complex represents an actionable drug target in p53-altered liver cancer. Nat Med. 2016;22(7):744-53.

59. Wang B, Hsu CJ, Chou CH, Lee HL, Chiang WL, Su CM, Tsai HC, Yang SF, Tang $\mathrm{CH}$. Variations in the AURKA gene: biomarkers for the development and progression of hepatocellular carcinoma. Int J Med Sci. 2018;15(2):170-5.

60. Nikulenkov F, Spinnler C, Li H, Tonelli C, Shi Y, Turunen M, Kivioja T, Ignatiev I, Kel A, Taipale J, et al. Insights into p53 transcriptional function via genome-wide chromatin occupancy and gene expression analysis. Cell Death Differ. 2012;19(12):1992-2002.

61. Calabrese V, Mallette FA, Deschenes-Simard X, Ramanathan S, Gagnon J, Moores A, llangumaran S, Ferbeyre G. SOCS1 links cytokine signaling to p53 and senescence. Mol Cell. 2009;36(5):754-67.

62. Yang S, Liu G. Targeting the Ras/Raf/MEK/ERK pathway in hepatocellular carcinoma. Oncol Lett. 2017;13(3):1041-7.

63. Chen $L$, Shi $Y$, Jiang $C Y$, Wei $L X$, Wang $Y L$, Dai GH. Expression and prognostic role of pan-Ras, Raf-1, pMEK1 and pERK1/2 in patients with hepatocellular carcinoma. Eur J Surg Oncol. 2011;37(6):513-20.

64. Tannapfel A, Sommerer F, Benicke M, Katalinic A, Uhlmann D, Witzigmann $\mathrm{H}$, Hauss J, Wittekind C. Mutations of the BRAF gene in cholangiocarcinoma but not in hepatocellular carcinoma. Gut. 2003;52(5):706-12. 
65. Calvisi DF, Evert M, Dombrowski F. Pathogenetic and prognostic significance of inactivation of RASSF proteins in human hepatocellular carcinoma. Mol Biol Int. 2012;2012:849874.

66. Calvisi DF, Ladu S, Gorden A, Farina M, Lee JS, Conner EA, Schroeder I, Factor VM, Thorgeirsson SS. Mechanistic and prognostic significance of aberrant methylation in the molecular pathogenesis of human hepatocellular carcinoma. J Clin Invest. 2007;117(9):2713-22.

67. Yue $X$, Zhao $Y, X u$ Y, Zheng M, Feng Z, Hu W. Mutant p53 in Cancer: accumulation, gain-of-function, and therapy. J Mol Biol. 2017;429(11):1595-606.

68. Rui L, Yuan M, Frantz D, Shoelson S, White MF. SOCS-1 and SOCS-3 block insulin signaling by ubiquitin-mediated degradation of IRS1 and IRS2. J Biol Chem. 2002;277(44):42394-8.

69. Ueki K, Kondo T, Tseng YH, Kahn CR. Central role of suppressors of cytokine signaling proteins in hepatic steatosis, insulin resistance, and the metabolic syndrome in the mouse. Proc Natl Acad Sci U S A. 2004:101 (28):10422-7.

70. Taniguchi CM, Winnay J, Kondo T, Bronson RT, Guimaraes AR, Aleman JO, Luo J, Stephanopoulos G, Weissleder R, Cantley LC, et al. The phosphoinositide 3-kinase regulatory subunit p85alpha can exert tumor suppressor properties through negative regulation of growth factor signaling. Cancer Res. 2010;70(13):5305-15.

71. Taniguchi CM, Tran TT, Kondo T, Luo J, Ueki K, Cantley LC, Kahn CR. Phosphoinositide 3-kinase regulatory subunit p85alpha suppresses insulin action via positive regulation of PTEN. Proc Natl Acad Sci U S A. 2006; 103(32):12093-7.

72. Li X, Mak VCY, Zhou Y, Wang C, Wong ESY, Sharma R, Lu Y, Cheung ANY, Mills GB, Cheung LWT. Deregulated Gab2 phosphorylation mediates aberrant AKT and STAT3 signaling upon PIK3R1 loss in ovarian cancer. Nat Commun. 2019;10(1):716.

\section{Publisher's Note}

Springer Nature remains neutral with regard to jurisdictional claims in published maps and institutional affiliations.

Ready to submit your research? Choose BMC and benefit from:

- fast, convenient online submission

- thorough peer review by experienced researchers in your field

- rapid publication on acceptance

- support for research data, including large and complex data types

- gold Open Access which fosters wider collaboration and increased citations

- maximum visibility for your research: over $100 \mathrm{M}$ website views per year

At $\mathrm{BMC}$, research is always in progress.

Learn more biomedcentral.com/submissions 